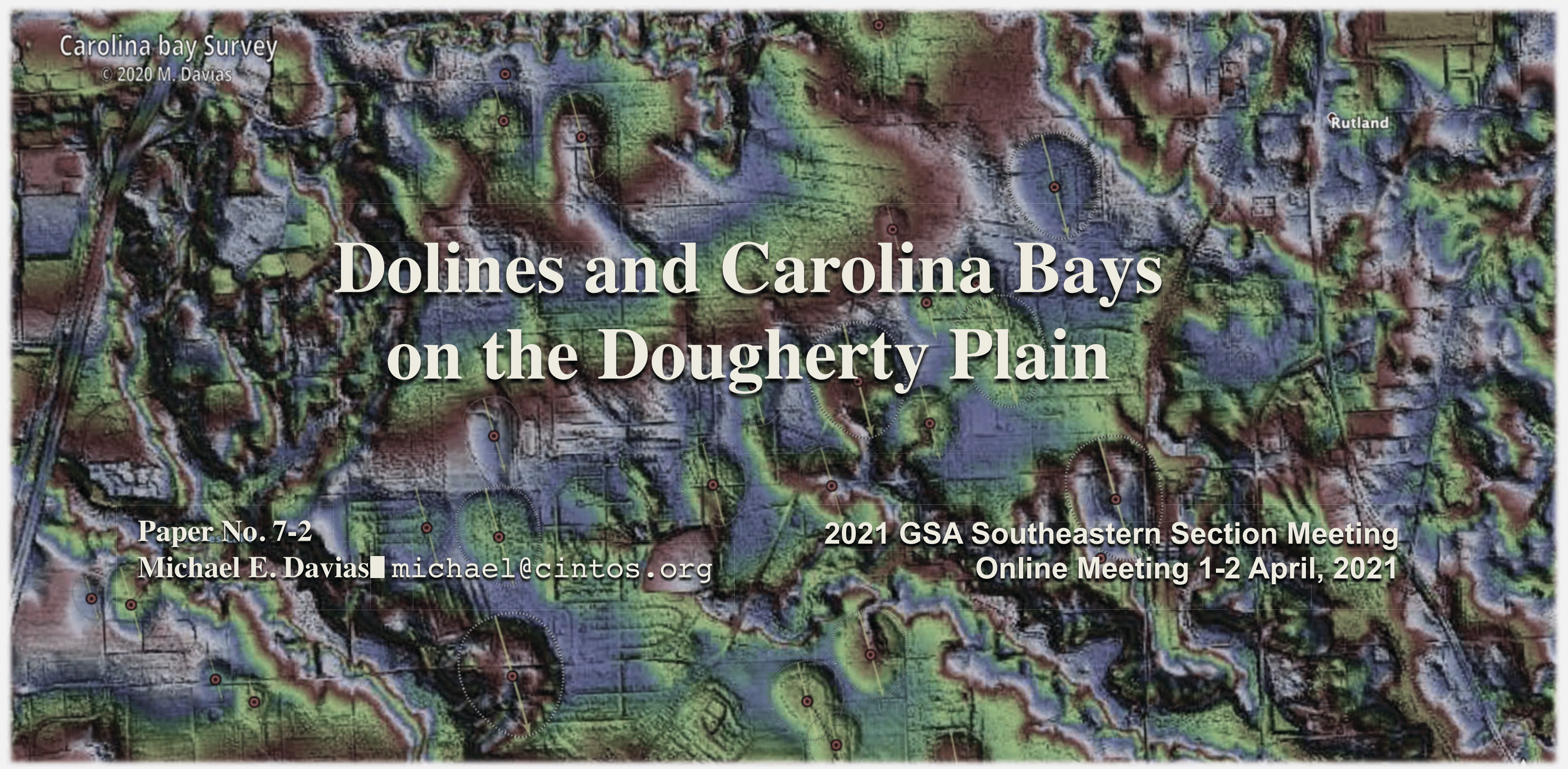

Session 7 - D4. Watersheds Local to Global II: Understanding Natural and Anthropogenic Influences on Rivers, Wetlands, and Coastal Environments GSA Abstracts with Programs. Vol. 53, No. 2, 2021 doi: 10.1130/abs/2021SE-362256 


\section{Goals of Talk}

It is my pleasure to share with you today my Carolina bay survey along with observations and subsequent deductions and speculations which may be applicable to the Dougherty Plain. I'll share my unconventional hypothesis for the Pleistocene evolution of the Dougherty Plain and socialize a geochronological tool to constrain North American sedimentary events over the past 5 Million years.

- Carolina bays as significant watershed components

- Dougherty Plain topographic province

- A Karst Terrain

- Hosts Carolina bays

- Carolina Bay Survey

- Unconventional hypothesis for Dougherty Plain geomorphology

- Geochronology Advances

- Cosmogenic Isotopes

- $\quad{ }^{10} \mathrm{Be} /{ }^{26} \mathrm{Al}$ capable back $5 \mathrm{My}$ 


\section{Full Disclosure}

- I'm sharing observations and informed speculation

- I propose that Carolina bays were not "excavated" from Costal Sediments

- Not by "wind \& wave" activities

- Not by direct or secondary cosmic impacts

- Carolina bays are far, far older than currently contemplated by geologists

All of which informs a speculative catastrophic hypothesis 
Dolines are well-documented subsidence sinkholes caused by suffosion of underlying carbonate bedrock. On the Dougherty Plain the bedrock agency is the Late Eocene Ocala Limestone.
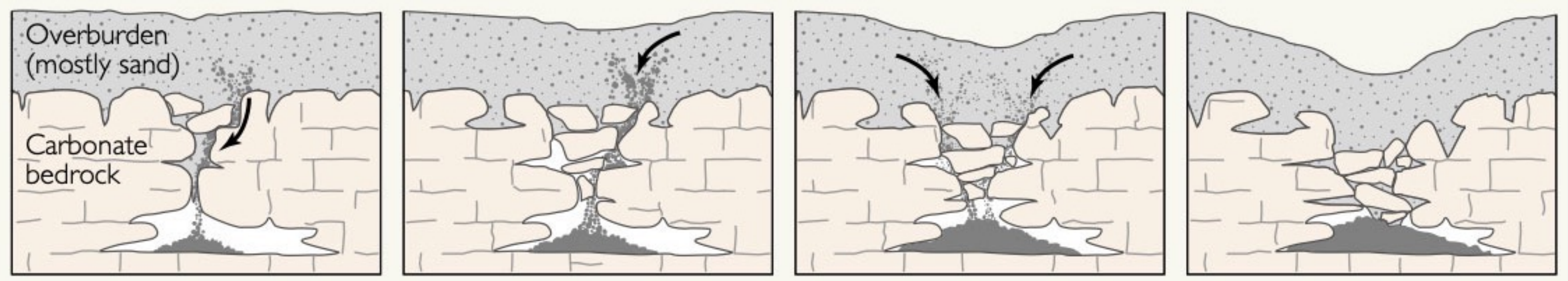

Ann B. Tihansky, 1999, Sinkholes, West-Central Florida, https://pubs.usgs.gov/circ/circ1 182/pdt/15WCFlorida.pdf

Dolines $=$ gentle subsiding sinkholes $=$ Karst
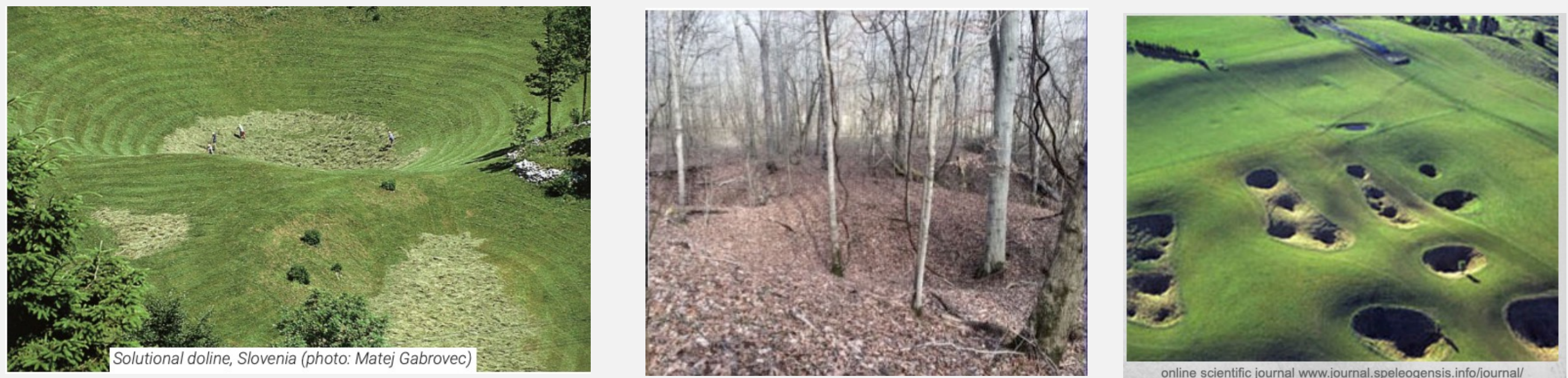


\section{Dolines $=$ gentle subsiding sinkholes $=$ Karst}

Mapping efforts have documented thousands of sinkholes on the Dougherty Plain.

A few are ovoids but otherwise jagged. Linear sequences of dolines are considered controlled by underground drainage channels, or bedrock fracture patterns.

G. Brook and T. Allison,1986, Fracture mapping and ground subsidence susceptibility modeling in covered karst terrain: the example of Dougherty County, IAHS-AISH, pp 595-606

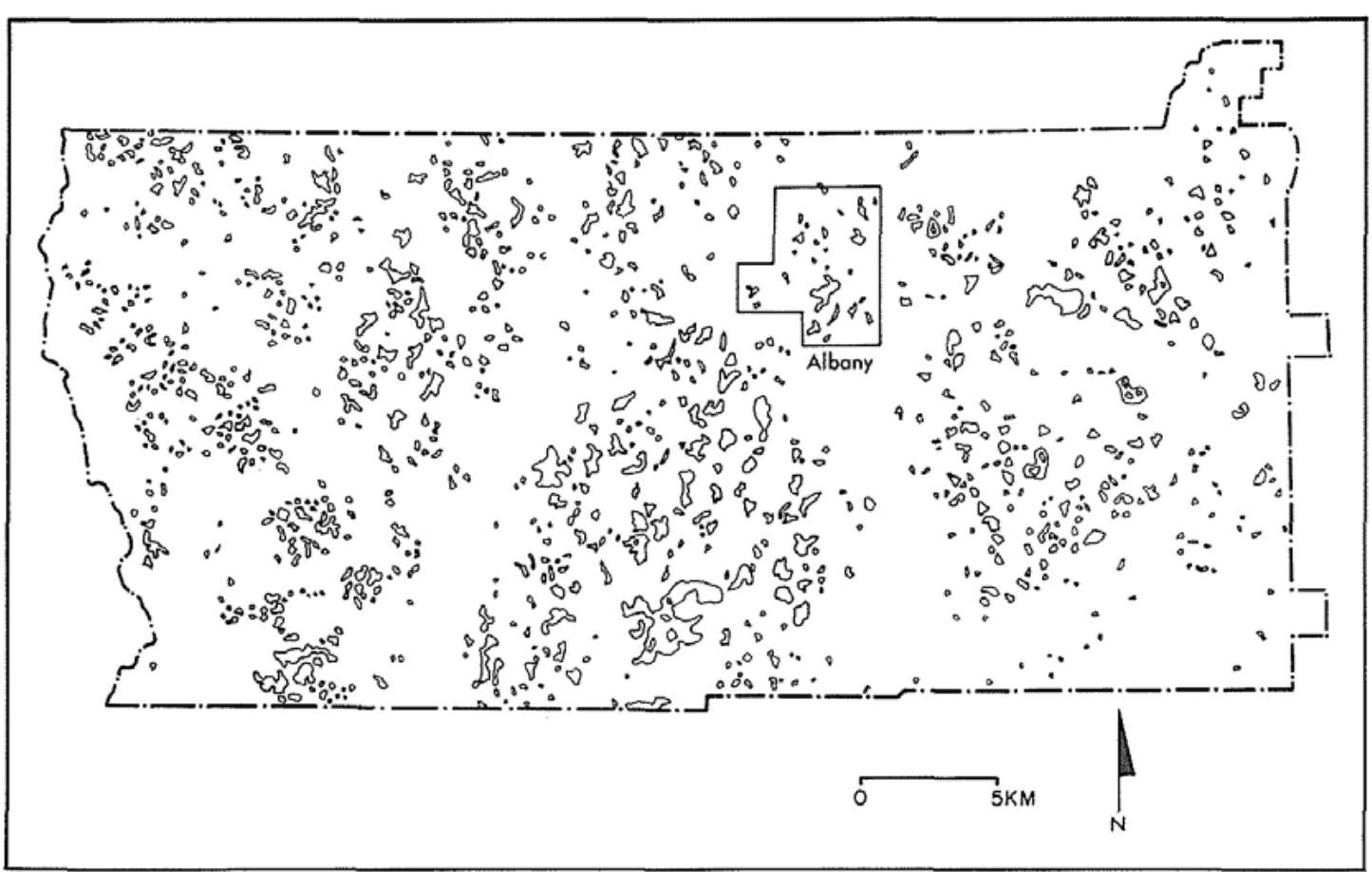

Fig. 1. The sinkholes of Dougherty County, Georgia. 


\section{Carolina bays}

When Douglas Johnson documented the planform of bays of North and South Carolina, he listed two. In the north, bays are more oval, and to the south, more tear-drop shape.

His findings validated the often-noted characteristics that the bay orientation varies systematically by latitude.

"In more than $\mathbf{4 0}$ years of geological study, the writer has not encountered a problem so difficult, unless it be that of submarine canyons." (Johnson, 1942, p4).
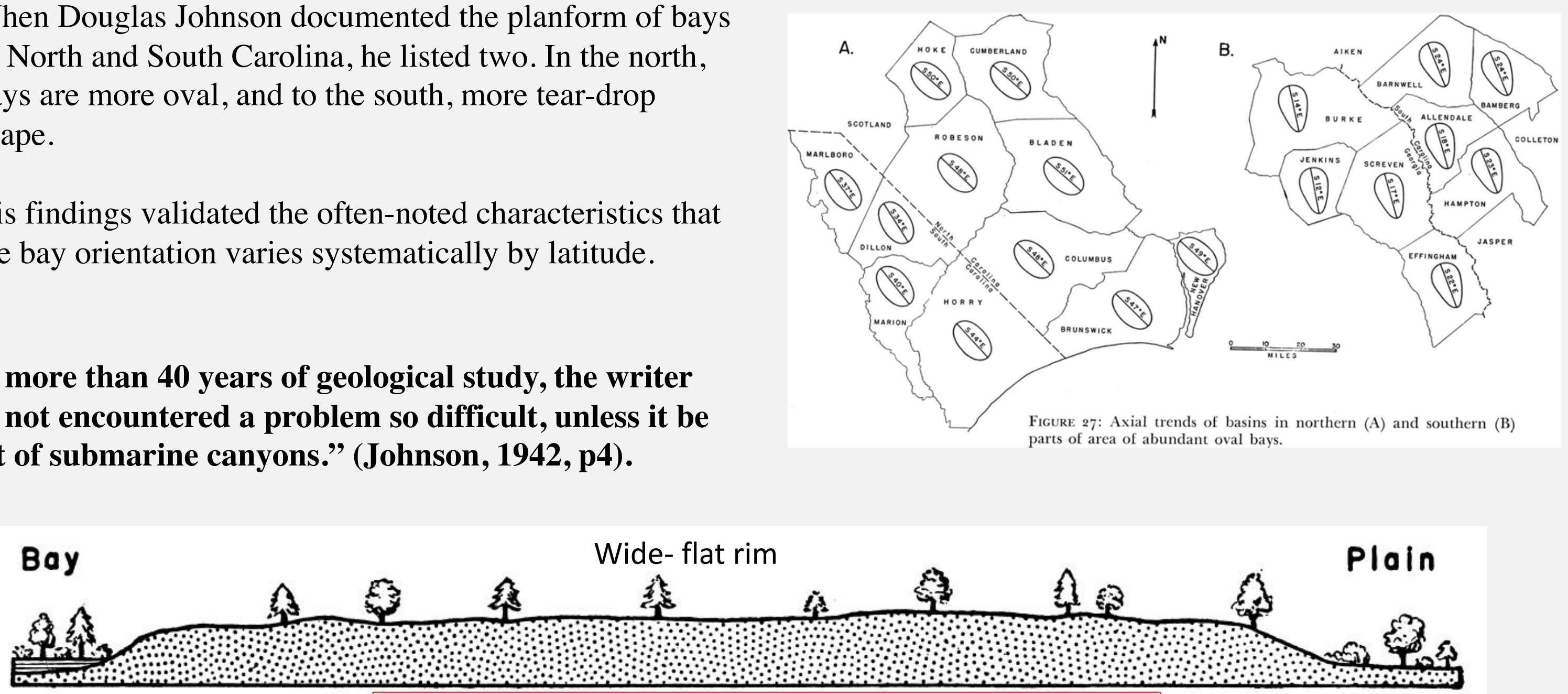

Douglas Johnson, 1942, The Origin of the Carolina Bays, Columbia University Press 


\section{Taxonomy of landform Genus "Carolina Bay”}

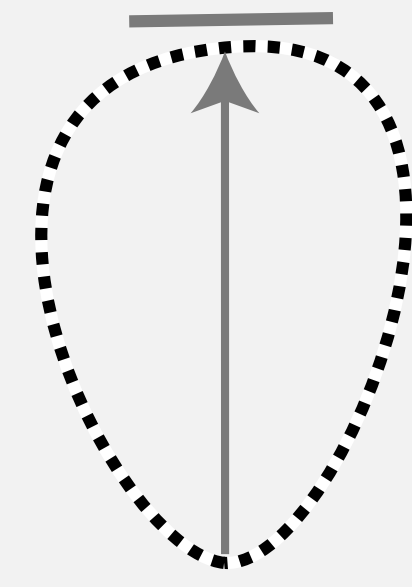

bayBell

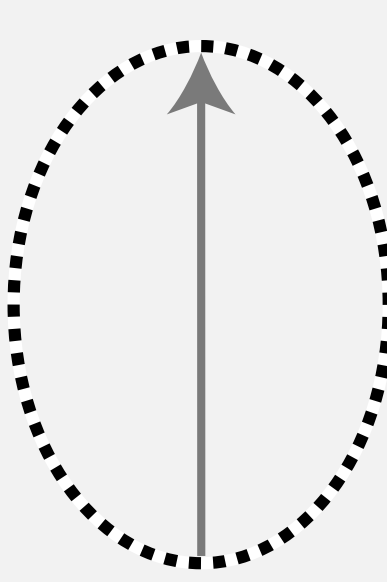

bayOval

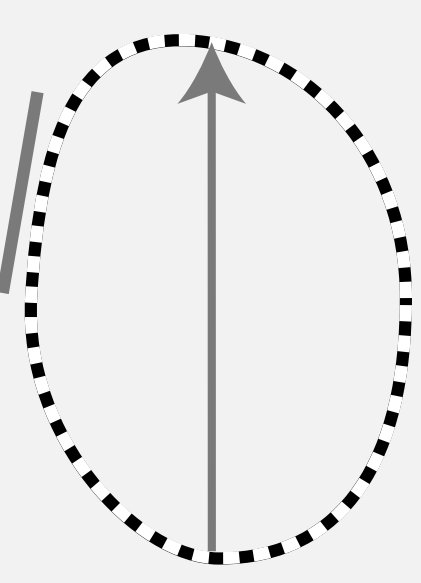

bayShore

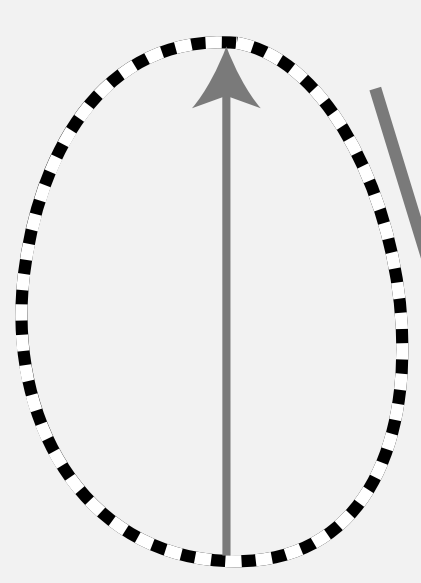

bayCarolina

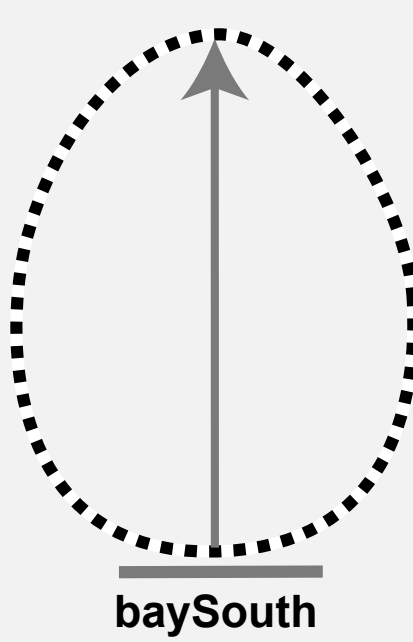

baySouth

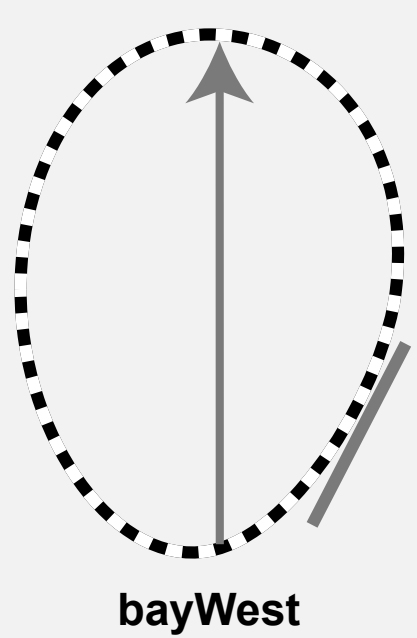

bayWest

I have identified Six species of Bays, that except for bayOval, possess a signature flattening.

Johnson's planforms bayCarolina and baySouth are highlighted), alll six found within exclusive territories. These templates are used in bay measurement, and their length and width can be shrunk or stretched to match a given bay, but otherwise the subtle yet unique modification from a pure oval are maintained. 
Here's a table showing simple averages of spatial size and eccentricity, by planform type. baySouth and bayCarolina represent $90 \%$ of all bays

\section{TABLE 1. STATISTICS OF 57,414 BAYS BY PLANFORM ARCHETYPE}

\begin{tabular}{|l|c|c|c|c|c|l|}
\hline \hline Archetype & $\begin{array}{c}\text { Surveyed } \\
\text { (count) }\end{array}$ & $\begin{array}{c}\text { Major Axis } \\
\text { mean }(\mathrm{km})\end{array}$ & $\begin{array}{c}\text { Eccentricity } \\
\text { mean }\end{array}$ & $\begin{array}{c}\text { Basin Area } \\
(\mathrm{Ha})\end{array}$ & $\begin{array}{c}\text { Contribution } \\
(\%)\end{array}$ & \multicolumn{1}{|c|}{ Region } \\
\hline bayOval & 114 & 0.273 & 0.594 & 4.47 & 0 & VA \& MD \\
\hline bayWest & 758 & 1.520 & 0.68 & 190.9 & 1 & NE \\
\hline bayShore & 817 & 0.530 & 0.61 & 26.4 & 2 & VA Eastern Shore \\
\hline bayBell & 4,580 & 0.206 & 0.4093 & 3.06 & 8 & NY, NJ, DE, MD \\
\hline baySouth & 24,950 & 0.330 & 0.63 & 11.8 & 43 & Southern SC to AL \\
\hline bayCarolina & 26,195 & 0.314 & 0.6923 & 5.58 & 46 & Northern SC and NC \\
\hline
\end{tabular}




\section{Histogram of bay size for various elevations}

While the shape changes, some metrics remain persistent. This histogram demonstrates the size distribution of $50,000+$ bays over various ranges of elevation above sea level.

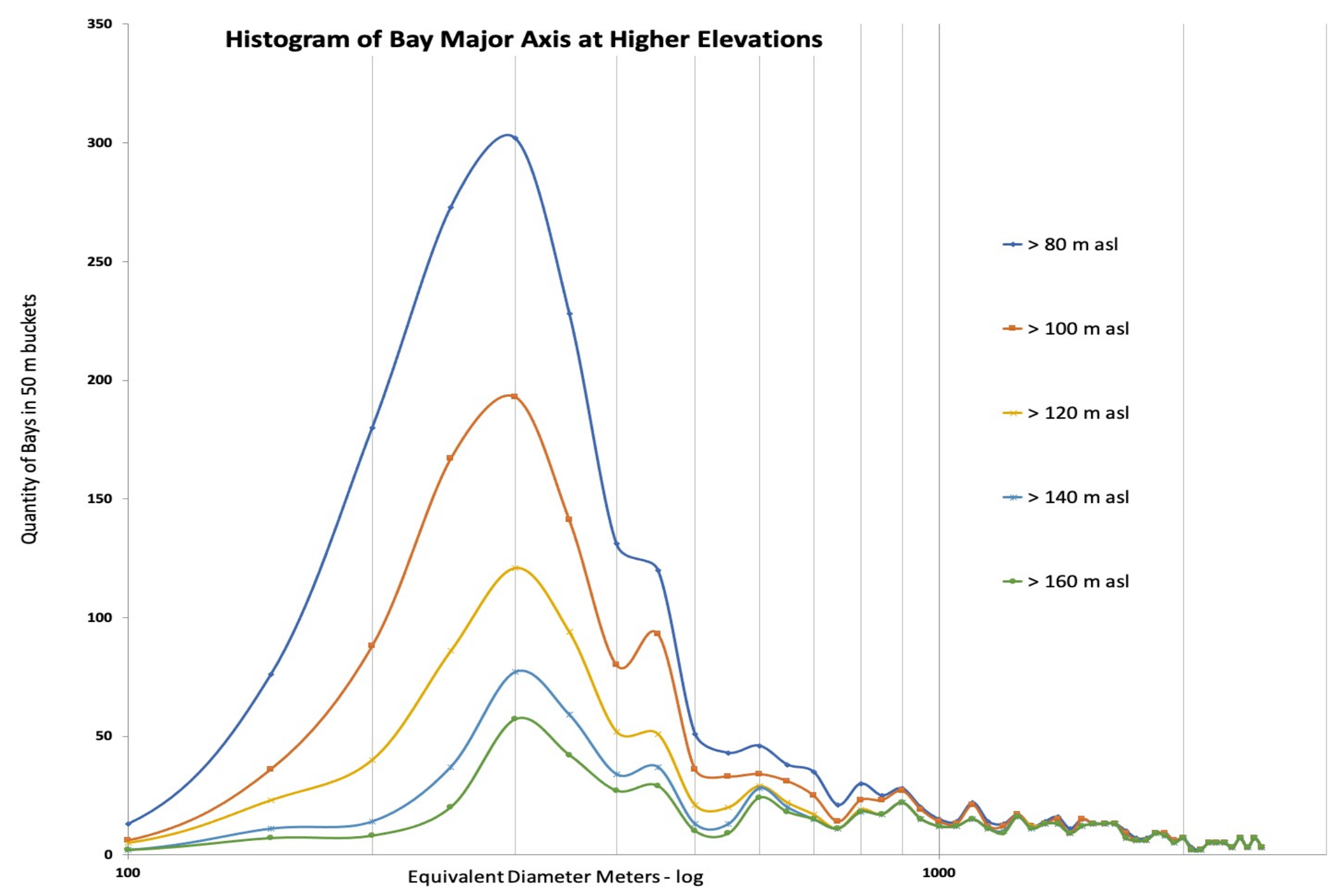




\section{Carolina bays}

Despite their prolific presence on the coastal plain, this story in Smithsonian Magazine is the ONLY article discussing Carolina bays in a major publicconsumption scientific periodical. Nat Geo? Discover? Scientific American? Nope.

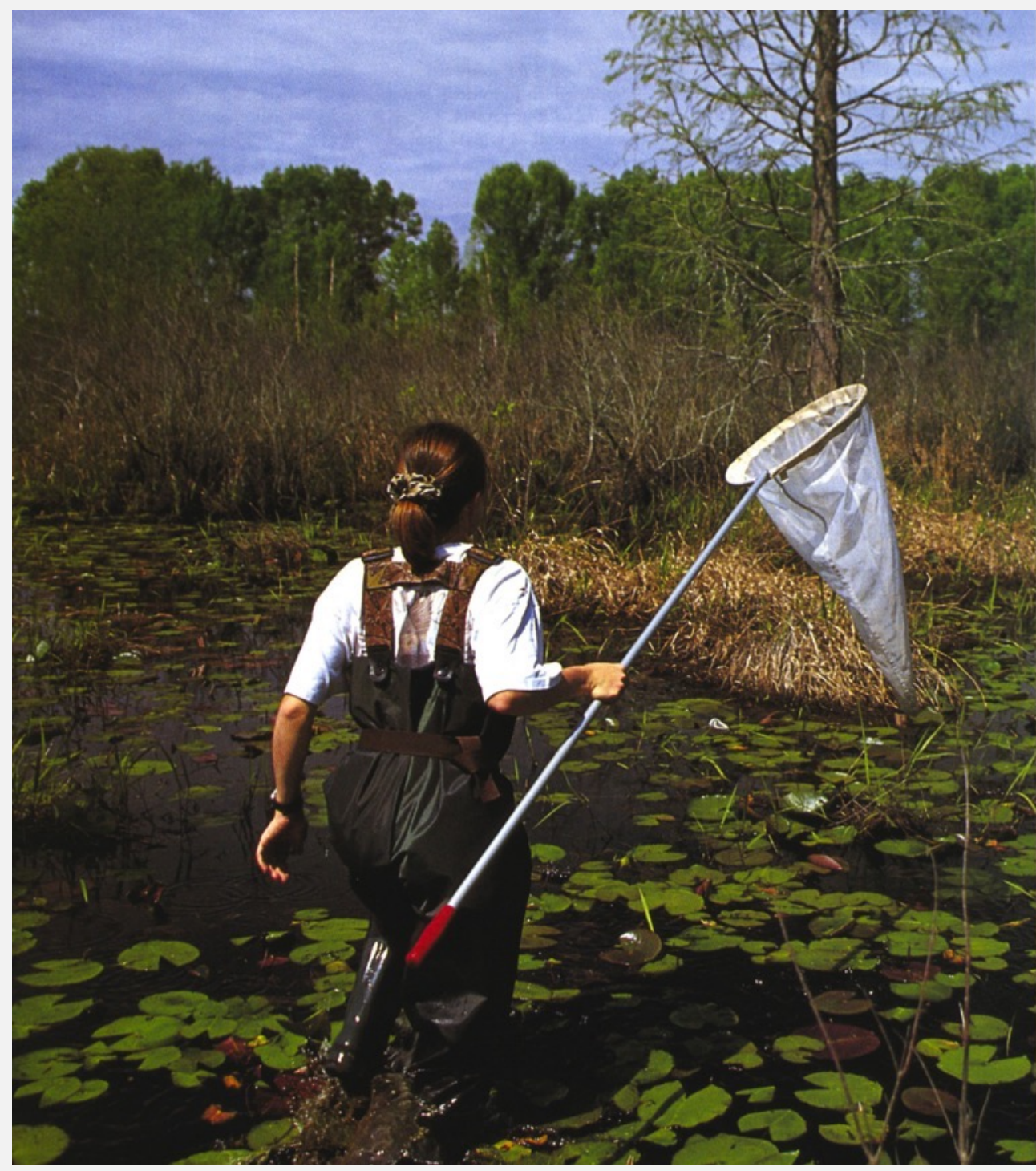

Riddle Carolina Bays

BY KEVIN KRAJICK 


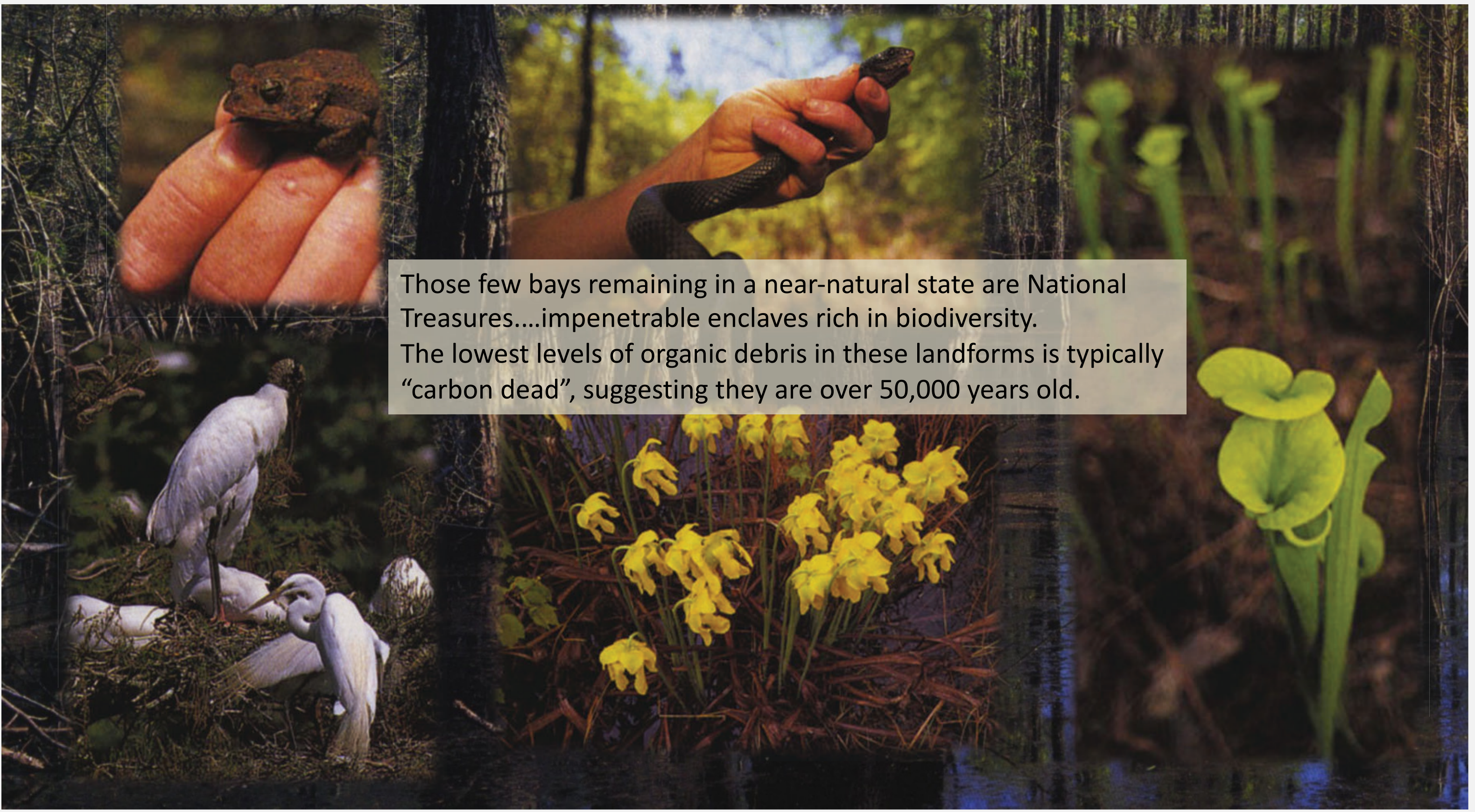


Antioch bay, NC. A truly beautiful emerald gem on a broad, flat interfluvial terrace.

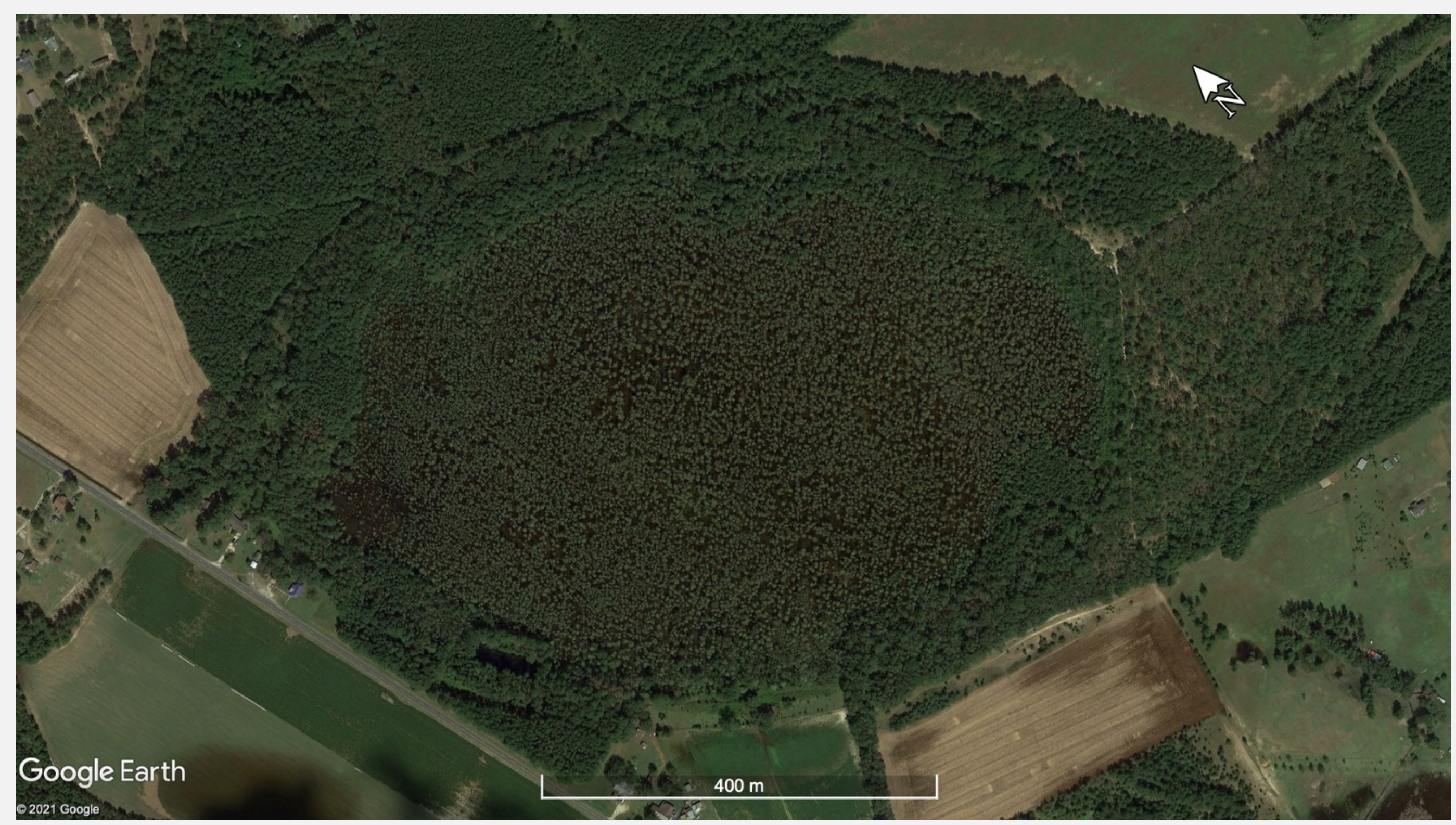




\section{Featured in this Smithsonian story is Antioch bay, in North Carolina.}

The topography of the landform is apparent in the LiDAR, revealing closed hydrology within an ovoid depression. Despite it's protected status, there is artificial drainage. A custom color ramp, on left, cycles every 10 meters, so elevations can be interpolated modulo $10 \mathrm{~m}$. The total relief in this image is under 5 meters. My protocol for the elevation model is to pump up the hill shading by 20 times, making such subtle relief look substantial. The imagery tiles in the cloud are rendered at 150 centimeters spatial resolution, a tradeoff between detail and download bandwidth. This is a significant catchment basin. Each meter of water in the basin yields 200,000 cubic meters of water. Is Antioch an unusually large bay? Actually, no.

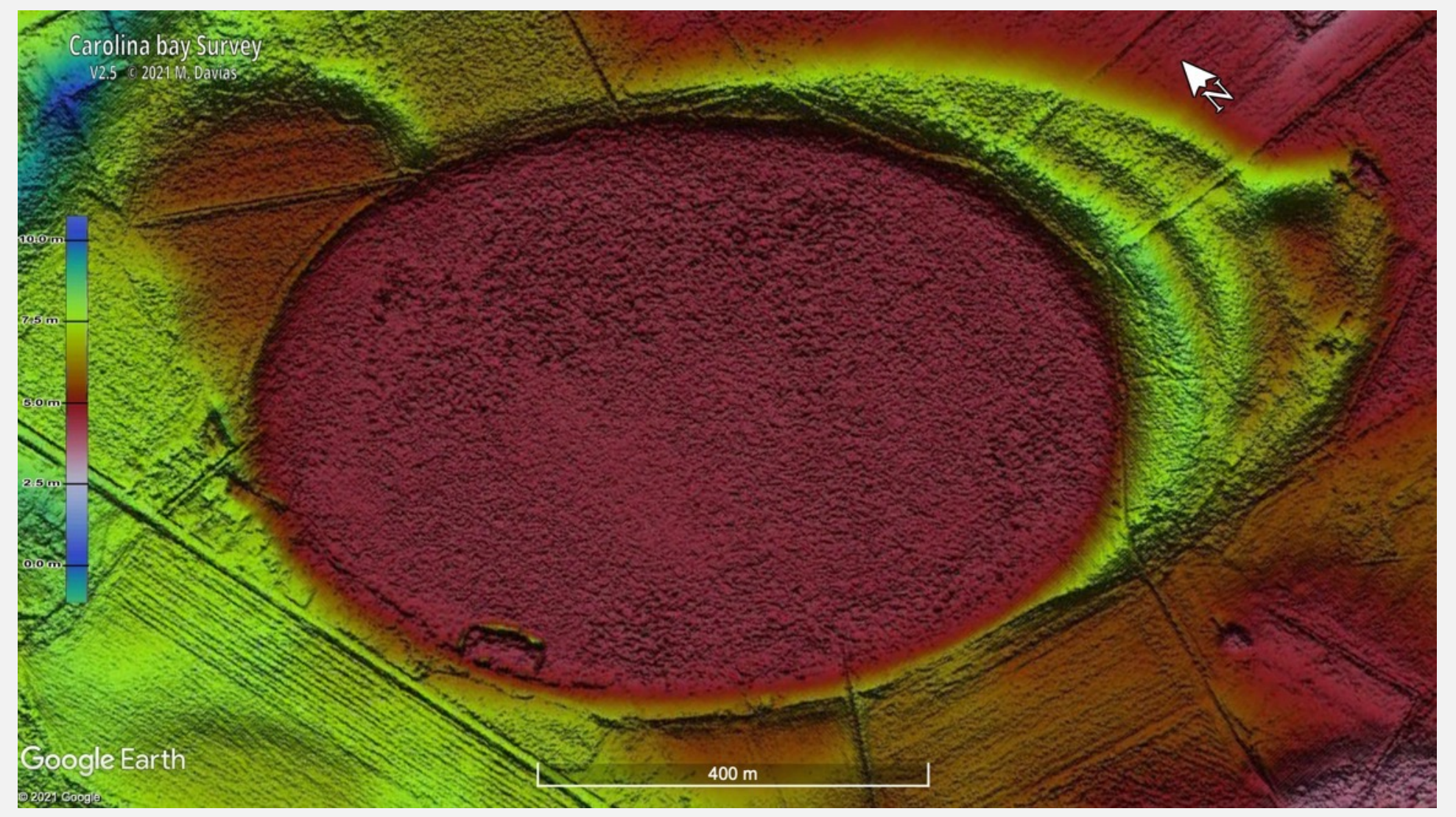

Each meter of water @ 961 m major, $652 \mathrm{~m}$ minor yields $\left(a^{*} b^{*} \pi\right)=200,000 \mathrm{~m}^{3}$ 


\section{0,000 Antiochs hold 2 Billion $\mathrm{m}^{3}$ \\ 1.6 Million Acre-Feet of water}

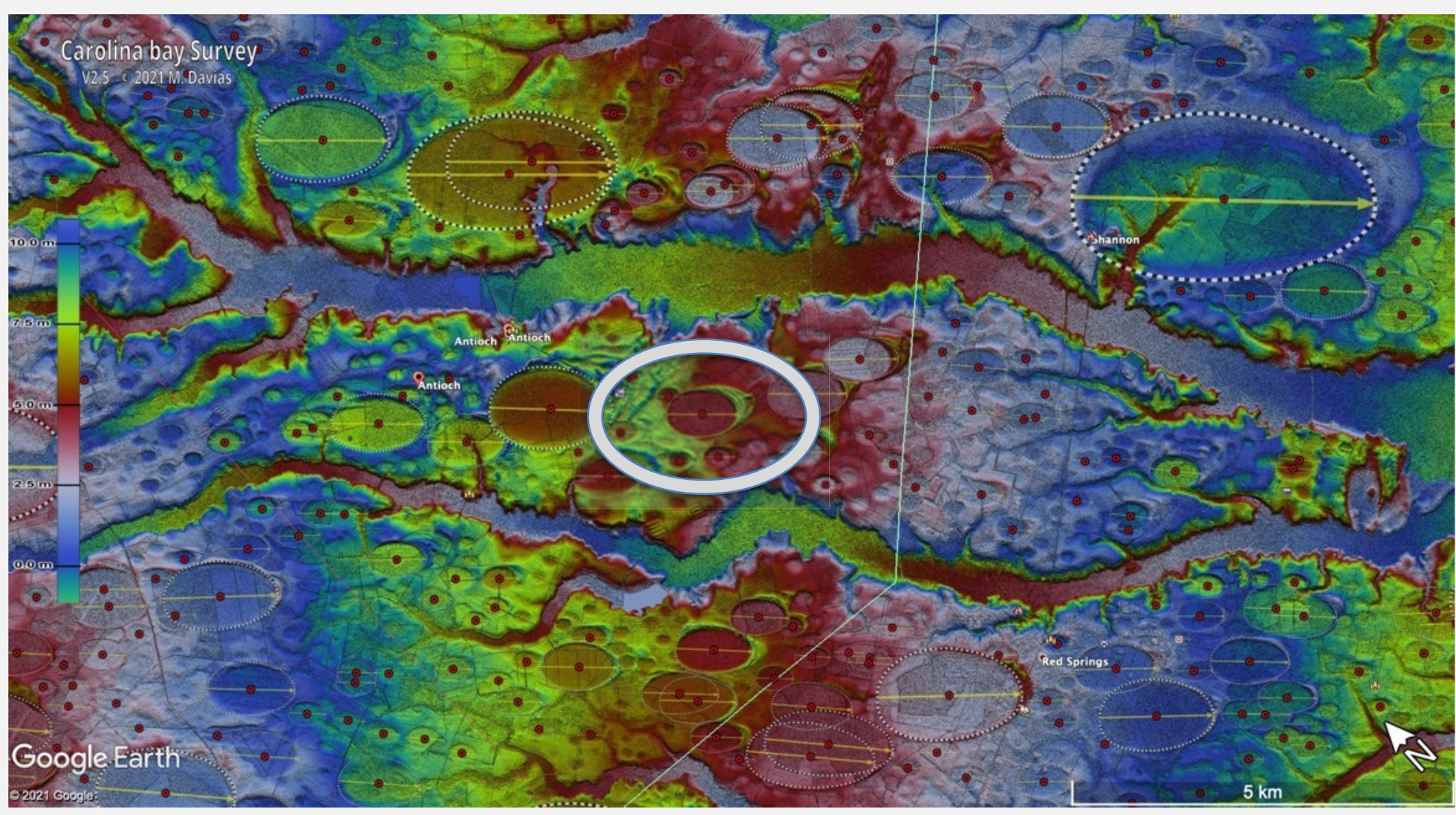

Backing out, with Antioch in the center, there are many of similar size. The survey documents over 10,000 bays that have main axis of over $1 / 2$ kilometer, within which the average size is 955 meters - like Antioch. A meter of standing water in those would yield a total of over 1.6 million acre feet of potential run-off catchment. The high rez topographic model elucidates the actual planform of the bays, without the obfuscation of foliage. It extends seamlessly across the survey scope. This image covers 200 square kilometers, yet the terrain has a relief of only 25 meters. Sadly, $99 \%$ of bays identified in the survey have been ditched and logged, with vast majority drained and converted to Human uses. 


\section{Anthropological Developrnent}
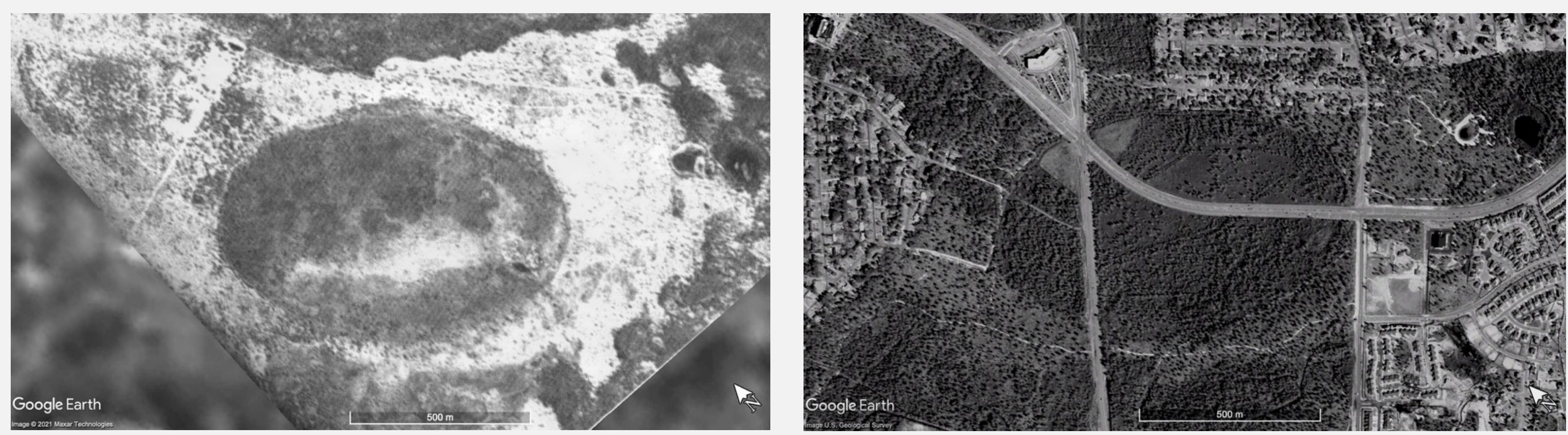

A 1930's aerial photo documents a bay with a major axis of over a kilometer.

Google historical imagery provides us this view in 1999, with graceful parkways through the longLeaf pine forest in Wilmington, NC. 
Anthropological Development
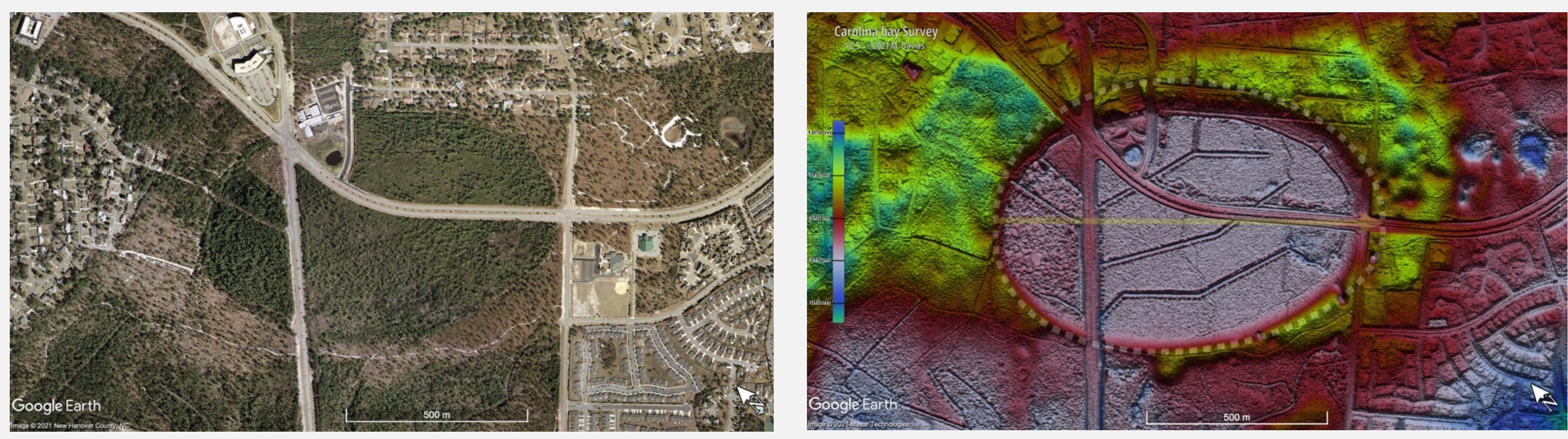

By 2011, the Cameron art museum had been built on the bay rim, along with a park and pond.

2014 LiDAR shows what's under the foliage ... lots of drainage. 


\section{Anthropological Developnent}
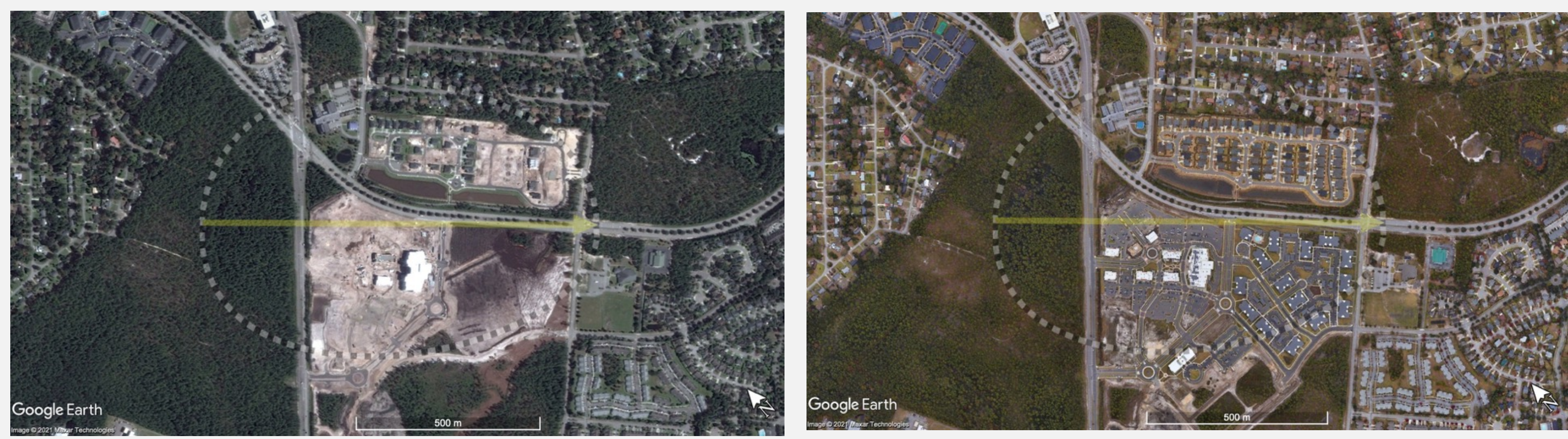

After 25 years of de-watering, it was ready for development underway in this 2016 satellite view.

Today it is a bustling community of homes, apartments, shopping, offices, the requisite cineplex and acres of asphalt parking and roofs.

I often contemplate what the flow rate of rivers look like today after a major hurricane, relative to after a similar storm centuries ago when these enormous catchment basins were buffering the hydrology. 


\section{Carolina bay Geosparial Survey}

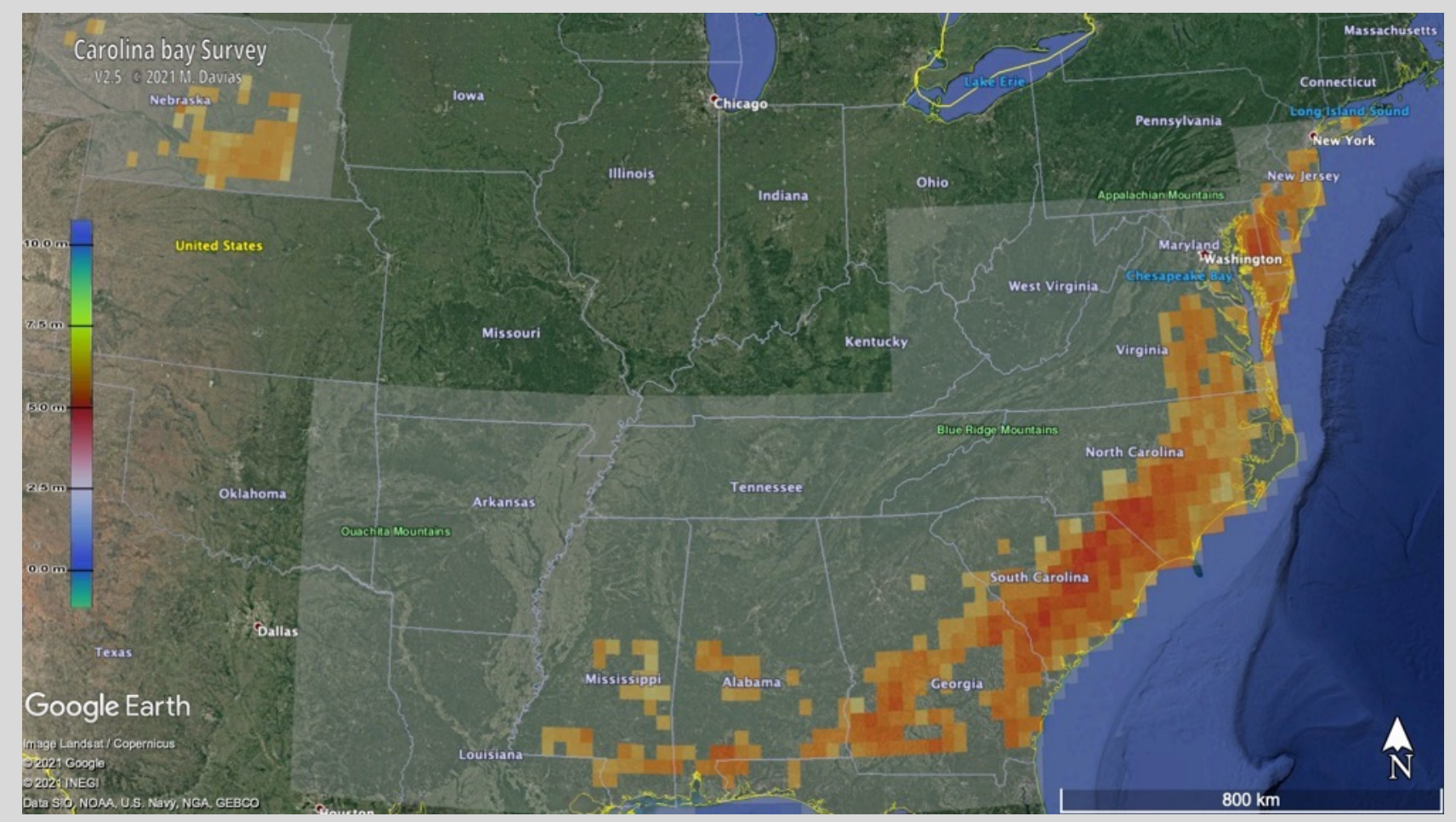

- Document $>55,000$ basins

- 200 USGS 10 Quadrants

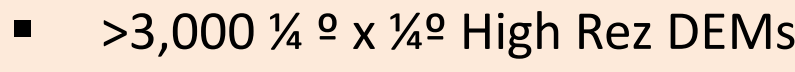

- Visualized on Google Earth

- Shot Patterns \& Groupings

- Planform Shapes

- Orientations

- Variety of Sizes

- Areas of No Basins

"Their very randomness of grouping and scatter demands an explanation. As a statistical phenomenon, they deserve to be studied statistically." W.C. Rasmussen, 1953 (GSA Fellow, 1956)

I have been assembling a geospatial survey of Carolina bays for the past decade. 55,000 basins are represented in this heat map view, across 2001 o quadrants, and imaged in over 3,000 one-quarter degree by one-quarter degree high resolution topographic digital models integrated into Google Earth. You might ask who inspired me to undertake such obscure research. It was GSA Fellow, and USGS hydrologist extraordinaire, William Rasmussen. "Their very randomness of grouping and scatter demands an explanation". He asserted, "As a statistical phenomenon, they deserve to be studied statistically." 


\section{Carolina bay Geospat?a! Survey}

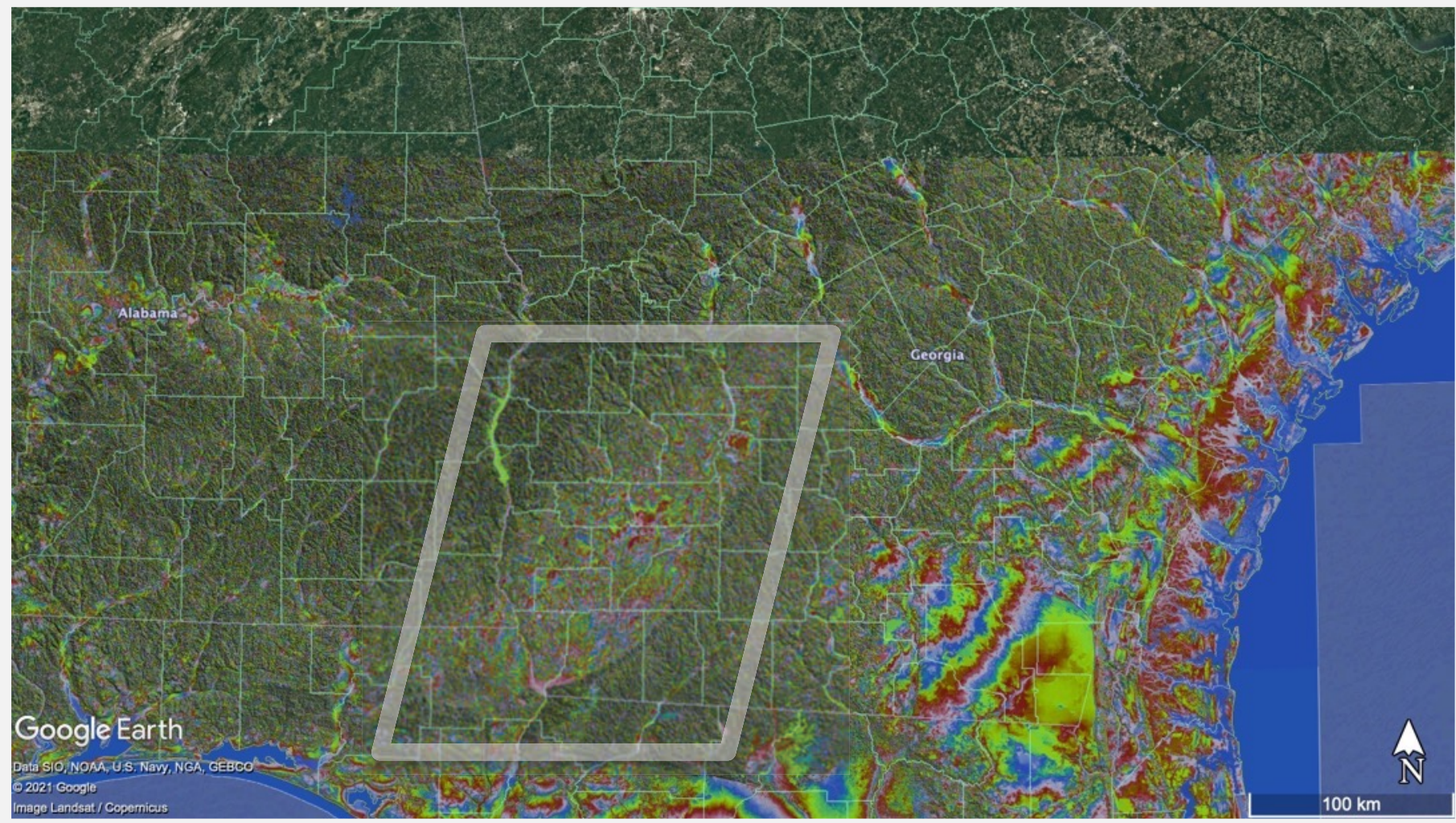

Now let's look closer to the southeastern US. ...zooming in tighter on a digital elevation model, regions of solid color denote low relief, as in the area highlighted. Carolina bays are often found on such flatter surfaces. ...this area coincides with the ACF river basin. 


\section{Carolina bay Geospatio Survey}

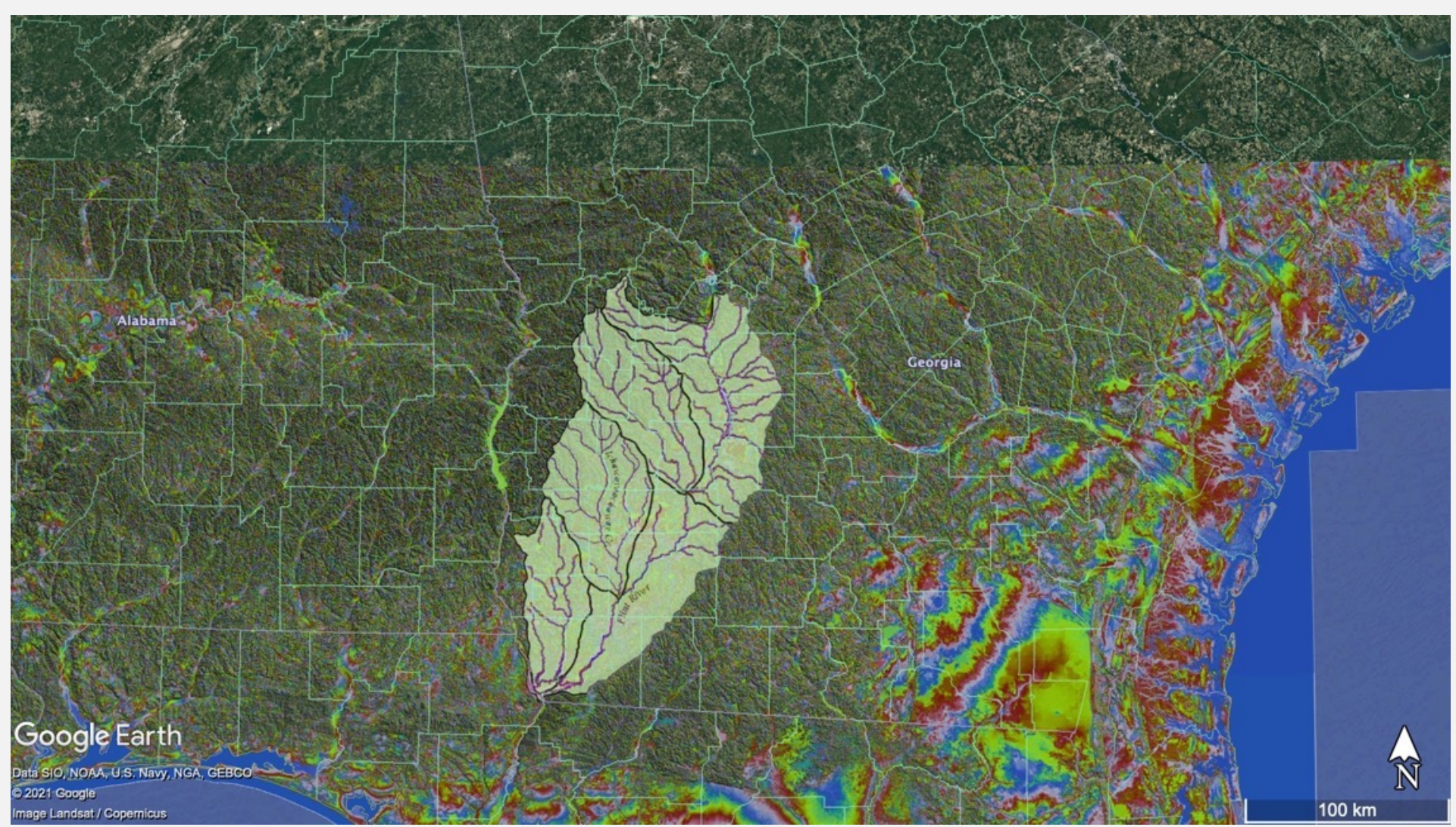

...this area coincides with the ACF river basin. The superimposed map is derived from Rugel, 2015. 


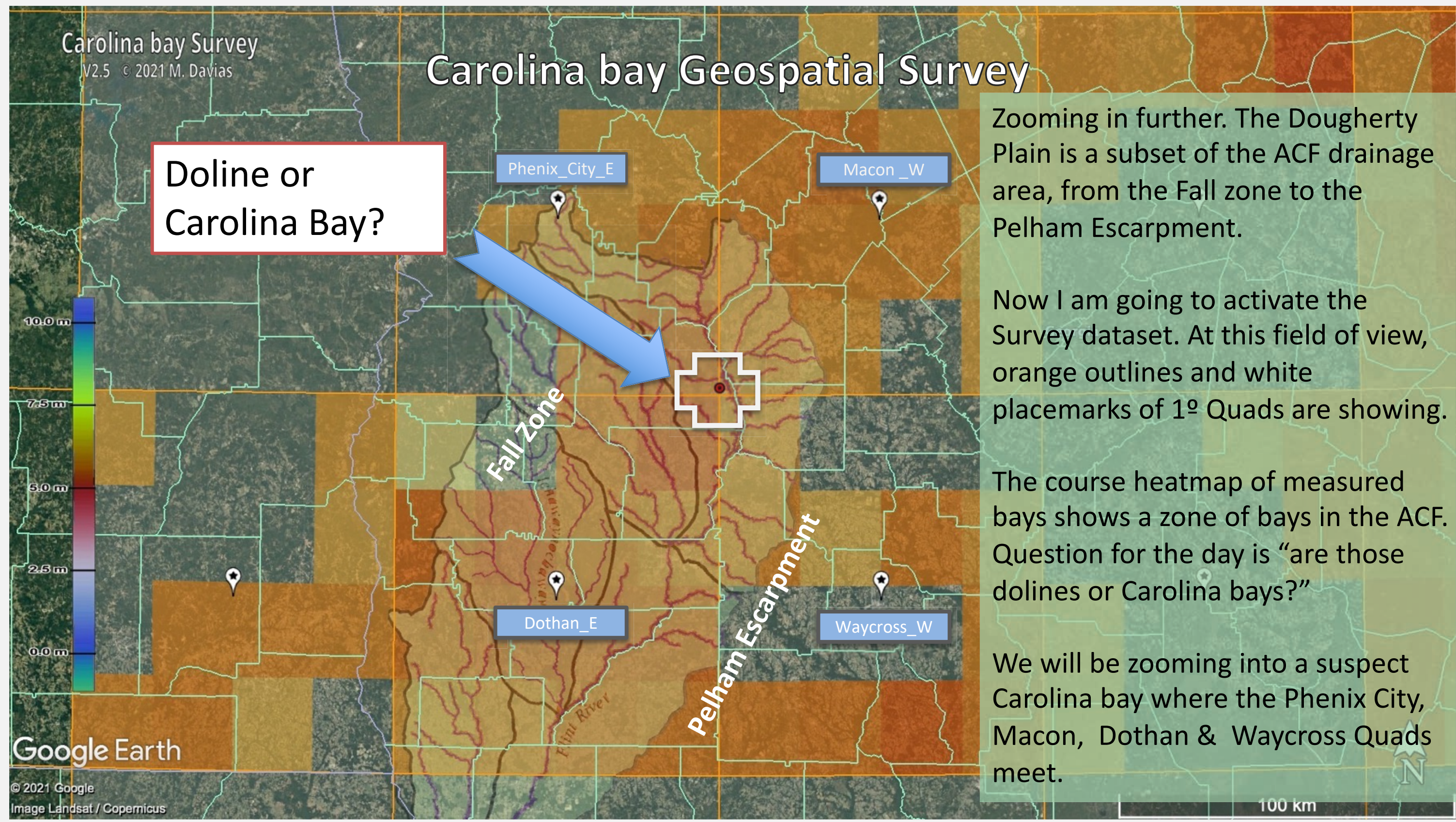




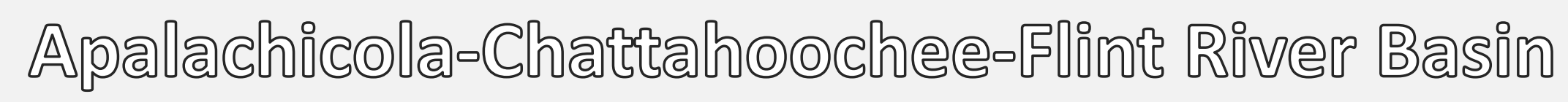

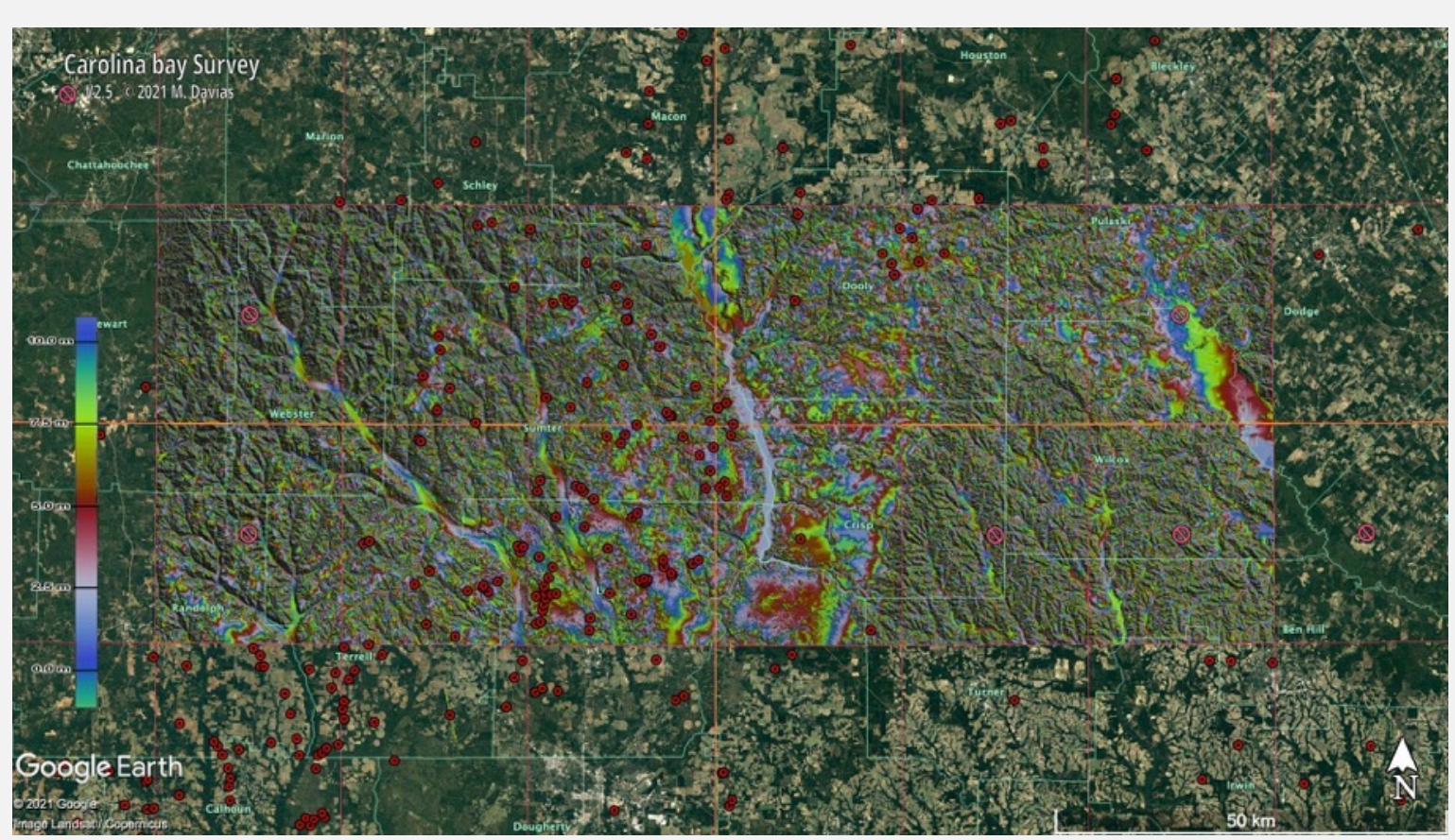

As the viewer moves in closer, the Survey presents placemarks for the largest $10 \%$ of bays in each $1 / 40$ quadrant, outlined in red.

The topographic model begins to load in the field of view.

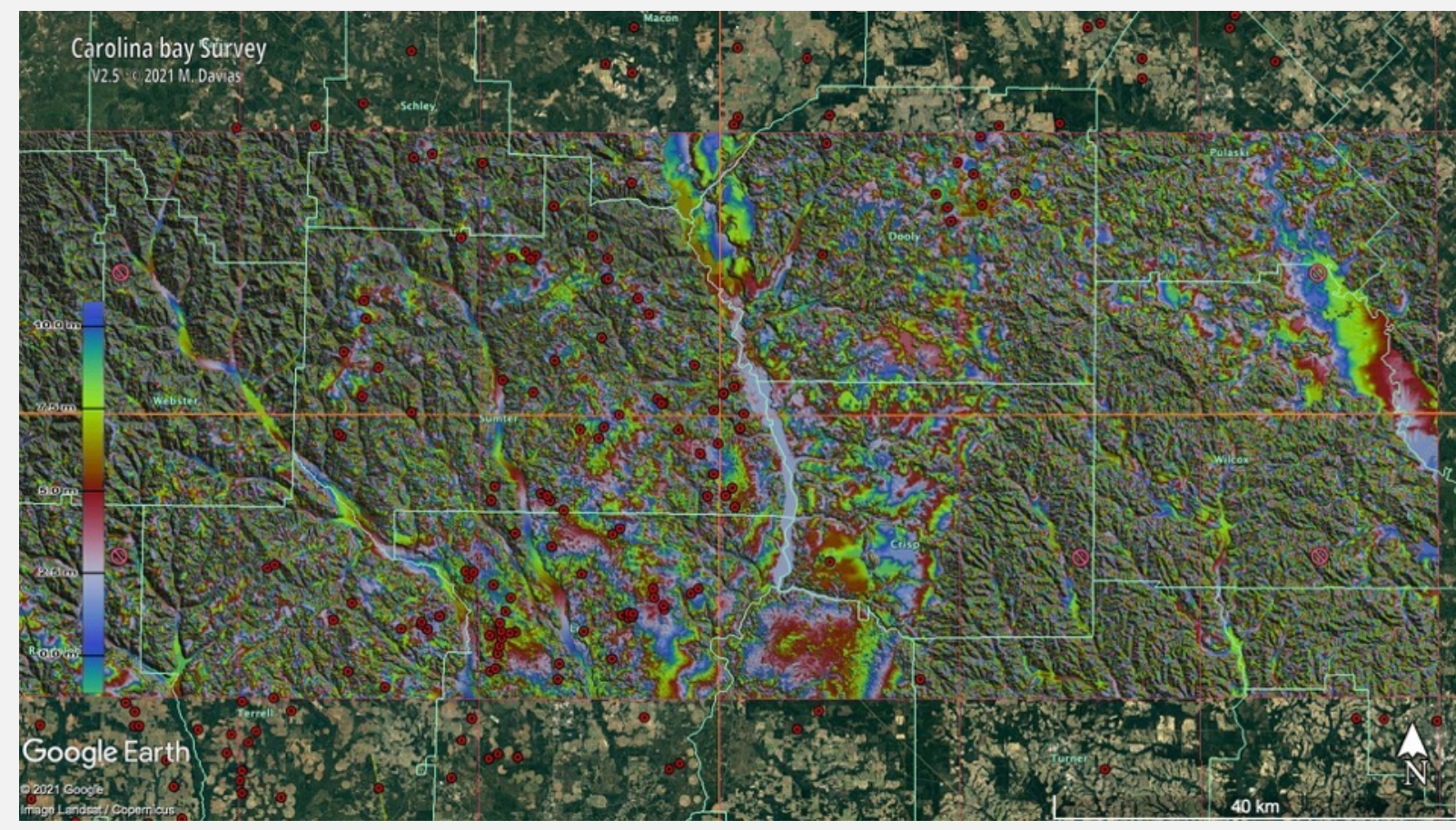

note that the "do not enter" icons denote $1 / 40$ quads that don't contain measured basins - but I'm always looking! 


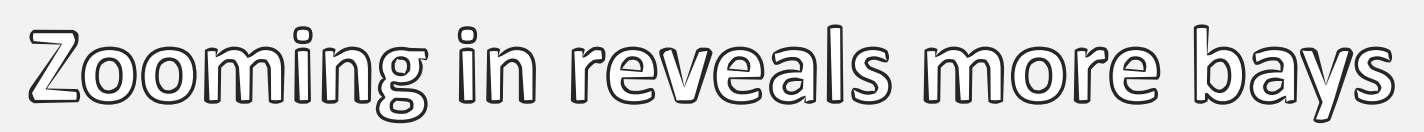
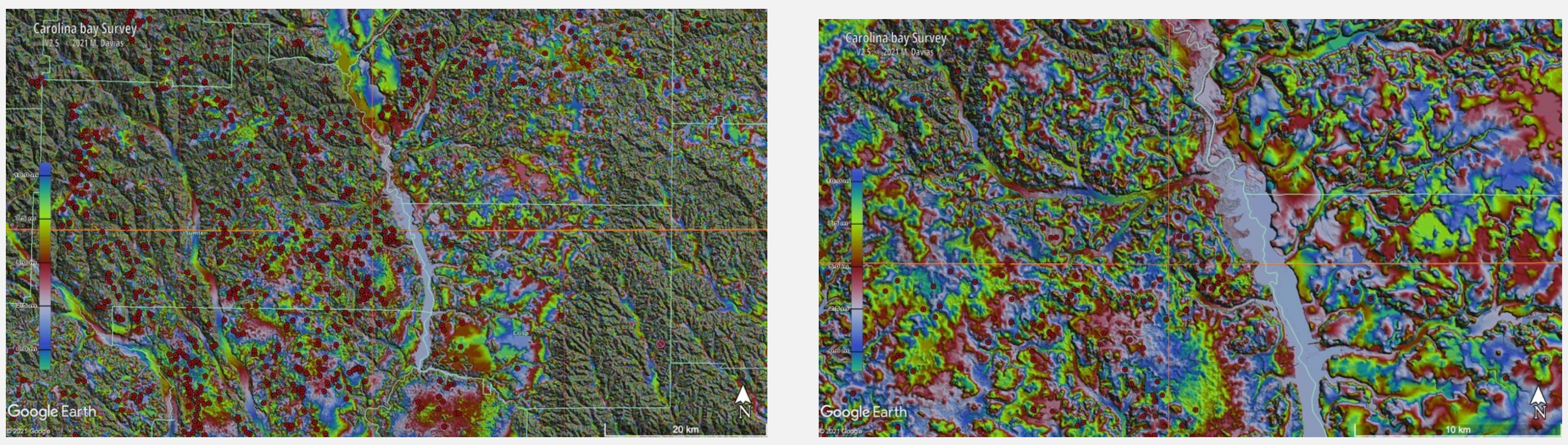

Zooming in further, ever higher rez maps load, along with the next $40 \%$ of bays. 


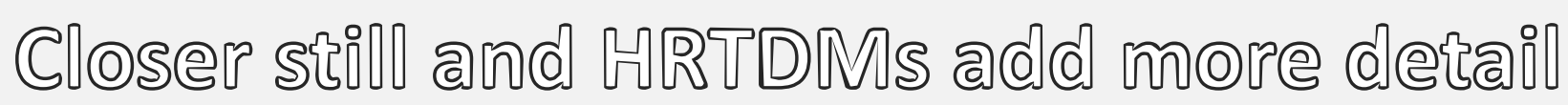

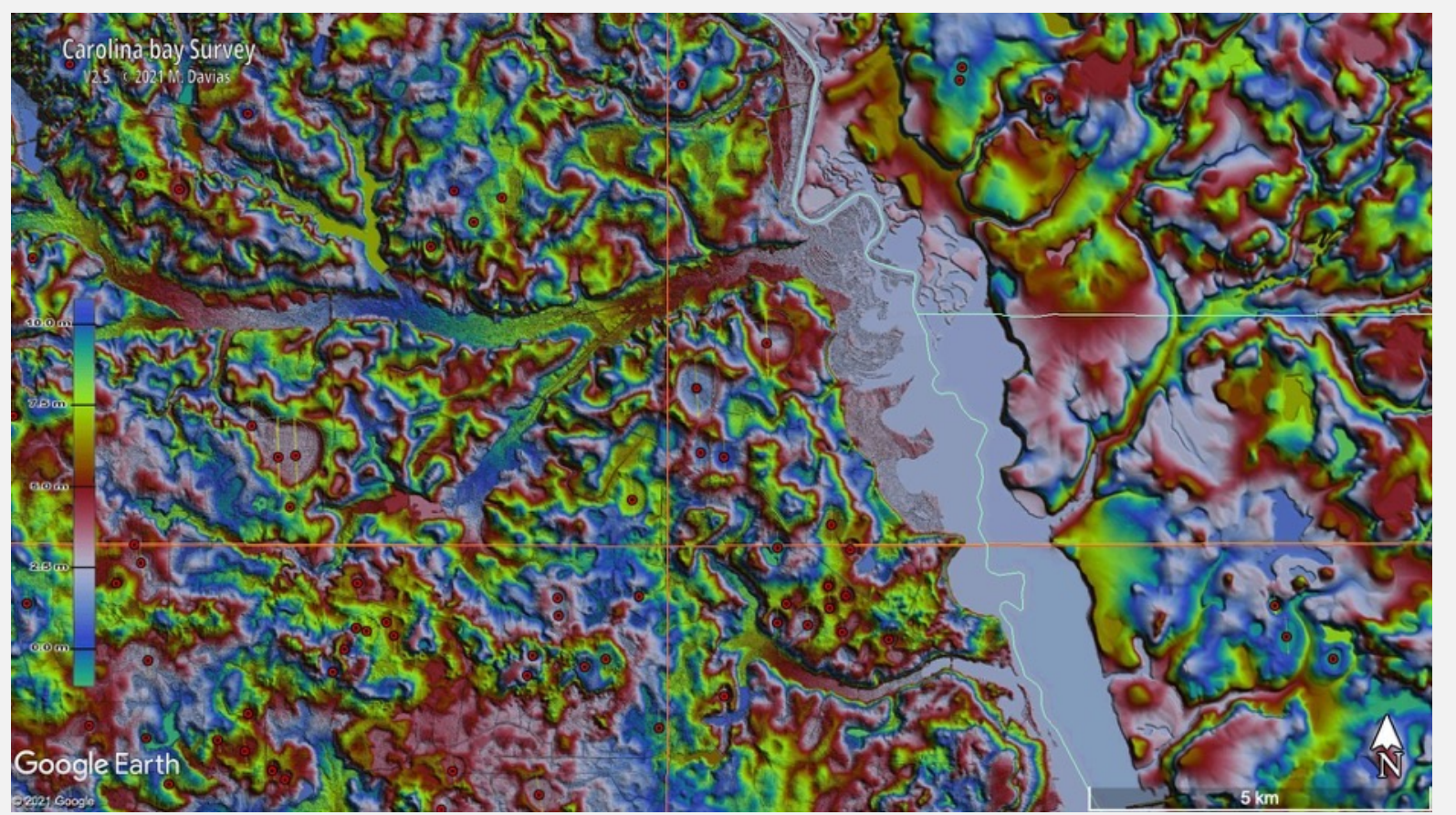

Soon the smallest $50 \%$ of bays load. The measurement overlays are beginning to be more visible

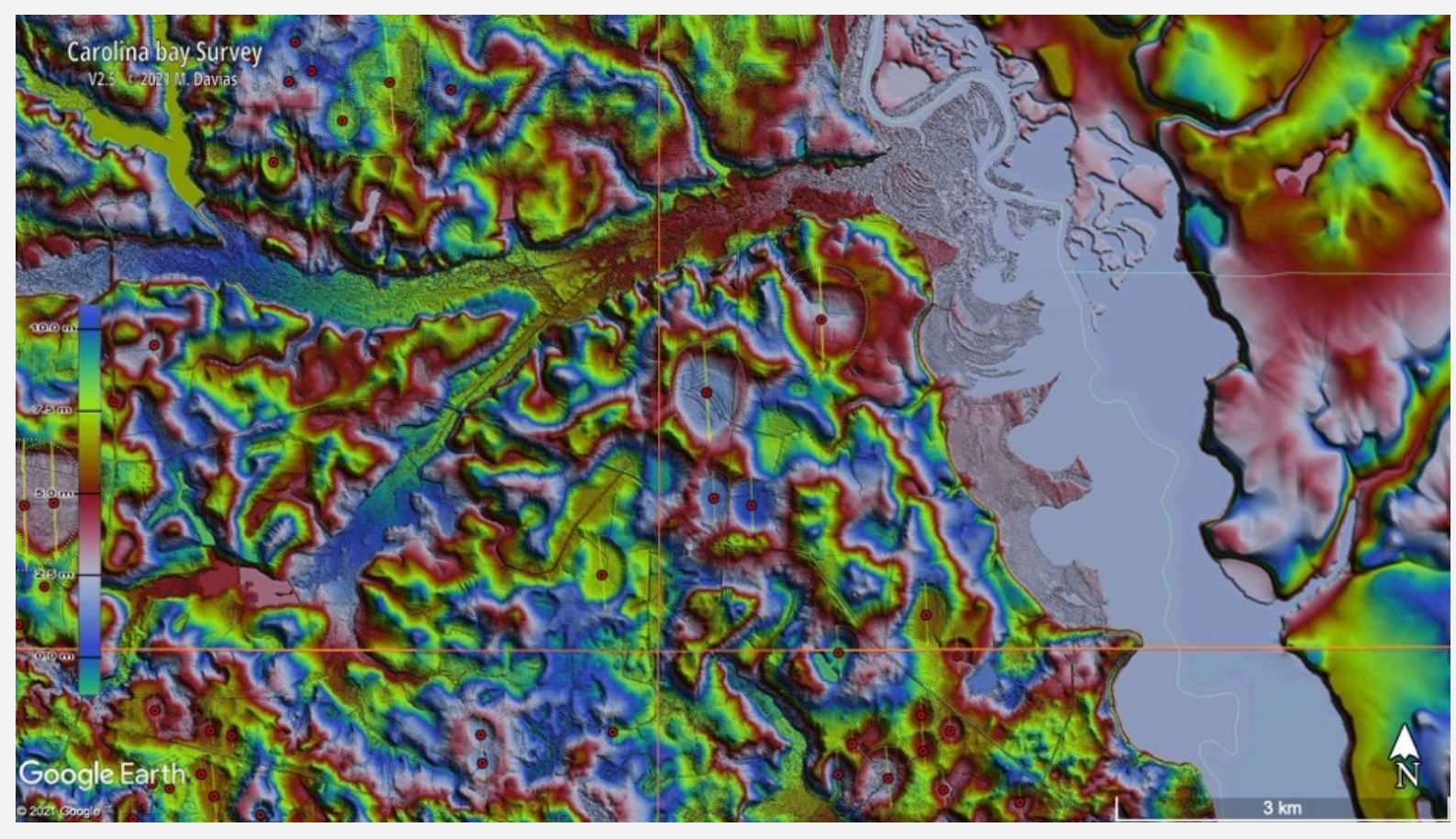

Sub-meter LiDAR is only available west of the Flint river here, data to the east is only sparse 10 meter. 
Survey nกอลsurenen overlays become clear
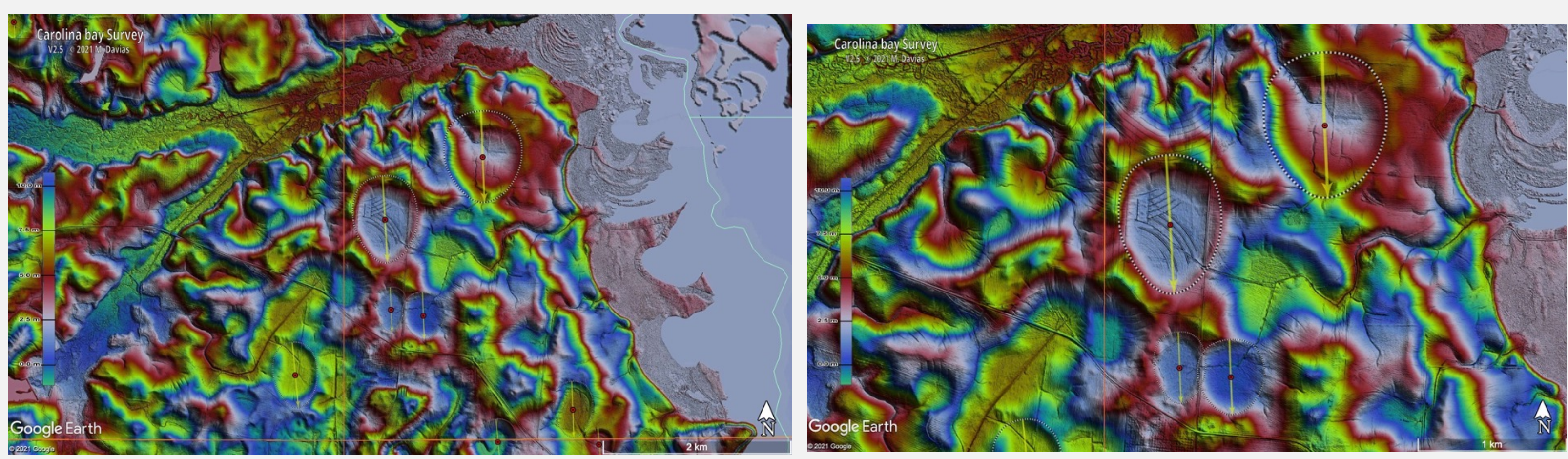

The landform in the center here, with a major axis of 926 meters

- like Antioch - is considered by me to be a Carolina bay, owing to its robust conformance to the planform and an orientation that is consistent with its neighbors. 


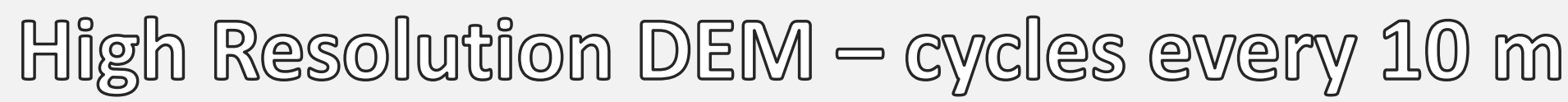
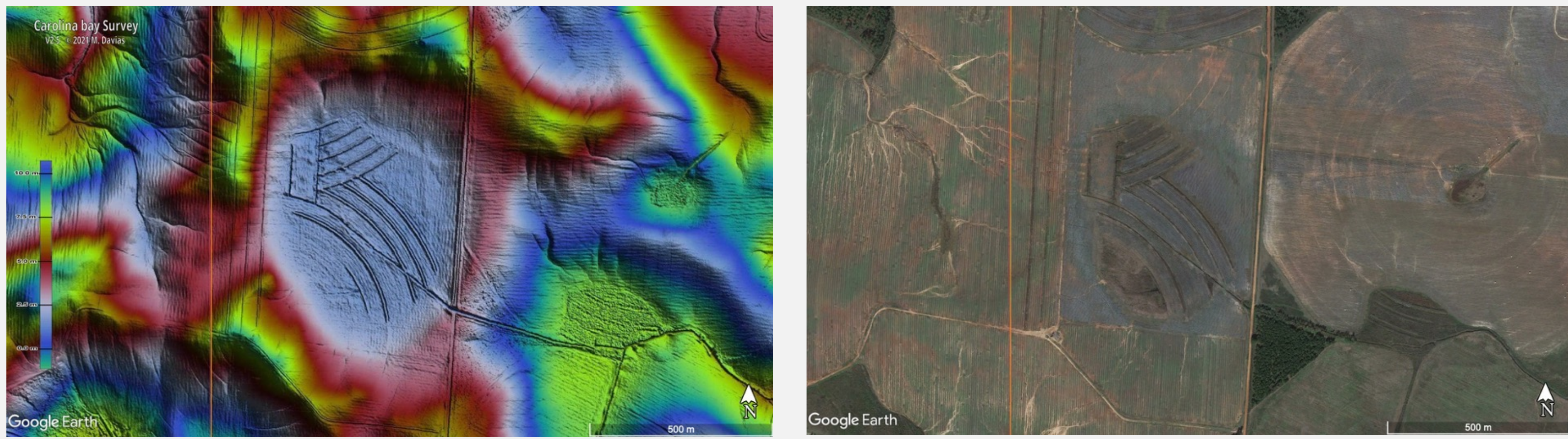

the value of sub-meter lidar becomes apparent when viewing the gentle arcs of irrigation rigs and other anthropological alterations.
Available orthophotography clearly cannot assist in discriminating the actual rim from the wetland. 


\section{Compare the two - differ by Eccentricity}
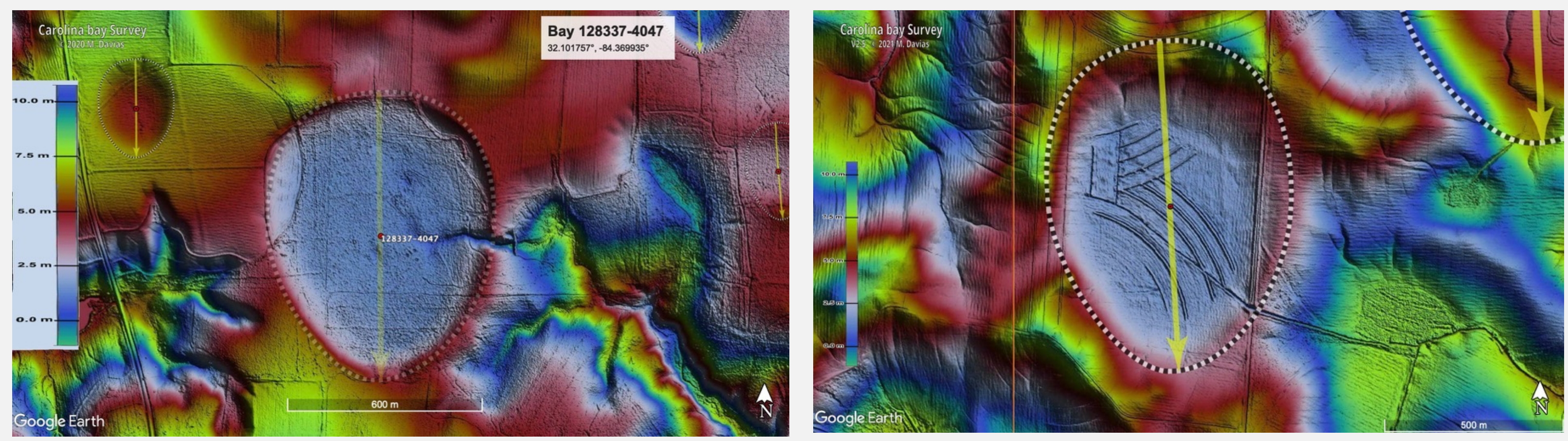

Located 34 kilometers to the west is another well-sculpted bay, again about 900 meters on major axis.

Note the similarity in planform to the previous Carolina bay, but having differing eccentricities.

It looks to be naturally drained by headward stream erosion which gained entry after being rebuffed across 800 meters of rim. 


\section{Templating a bay for measurements}

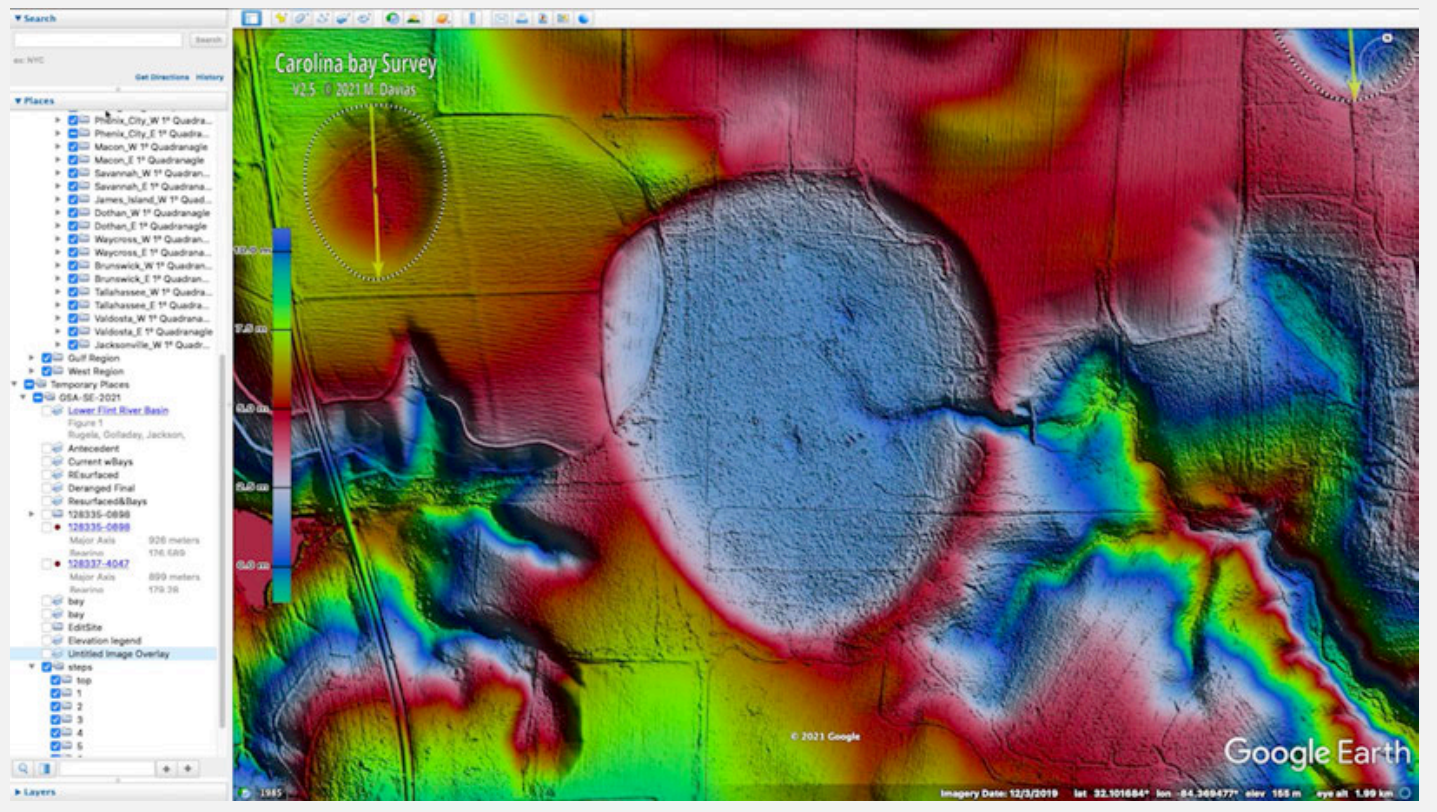

Video available for download: GSA SE-2021 BayMeasurement.mp4

Let's have a look at my bay measurement Protocol. First a new image overlay is added to the Google Earth directory of metadata, in the left panel, We provide a name and a url to the template image. It is instantiated with the arrow pointing due north. It is edited with the corner and rotation handles, fitting the template to the bay's rim. While some of the outcome is subjective, the subtle variation of the archetype oval help lock-in result. Templating provides a precise and reproducible measurement protocol while remaining highly efficient compared to manually tracing. The goal is to encompass the rim under the dotted line. 


\section{Keyhole Markup Language Data in GroundOverlay}

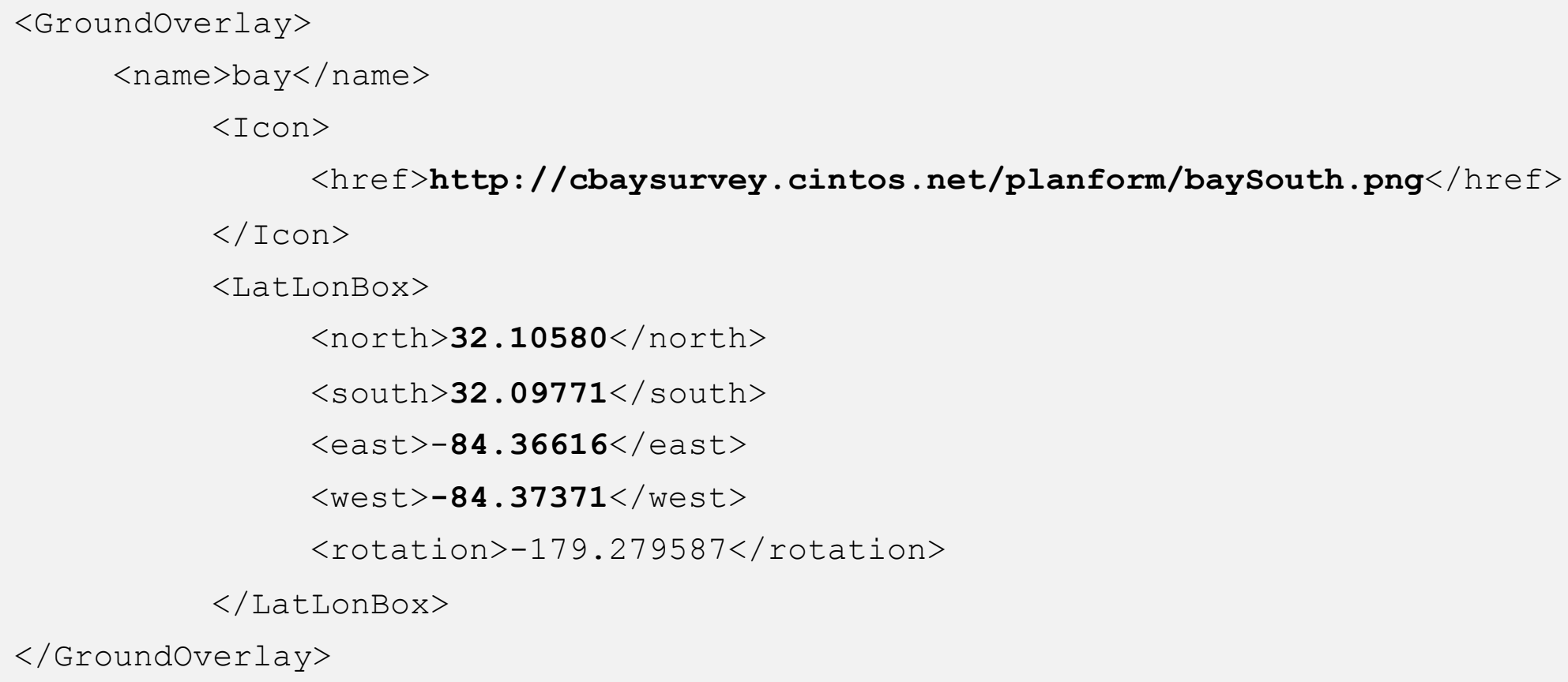

Now, a ground overlay element is not a graphic image - it is text in a mark-up language . We can read this:

The baySouth overlay's url is identified. The rotation from due north reports the bay' s orientation.

The GroundOverlay metadata's bounding box defines (with a bit of trig) the major and minor axis of the bay, a bay center, and an approximate surface area. Coordinates ( 5 decimal places reflects 1 meter accuracy) define the box with zero rotation applied. 


\section{GroundOverlay LatLonBox Computations}

...create a bounding box that defines (with a bit of trig) the major and minor axis of the bay, a bay center, and an approximate surface area.

The box is defined with zero rotation, which is re-applied when displayed.

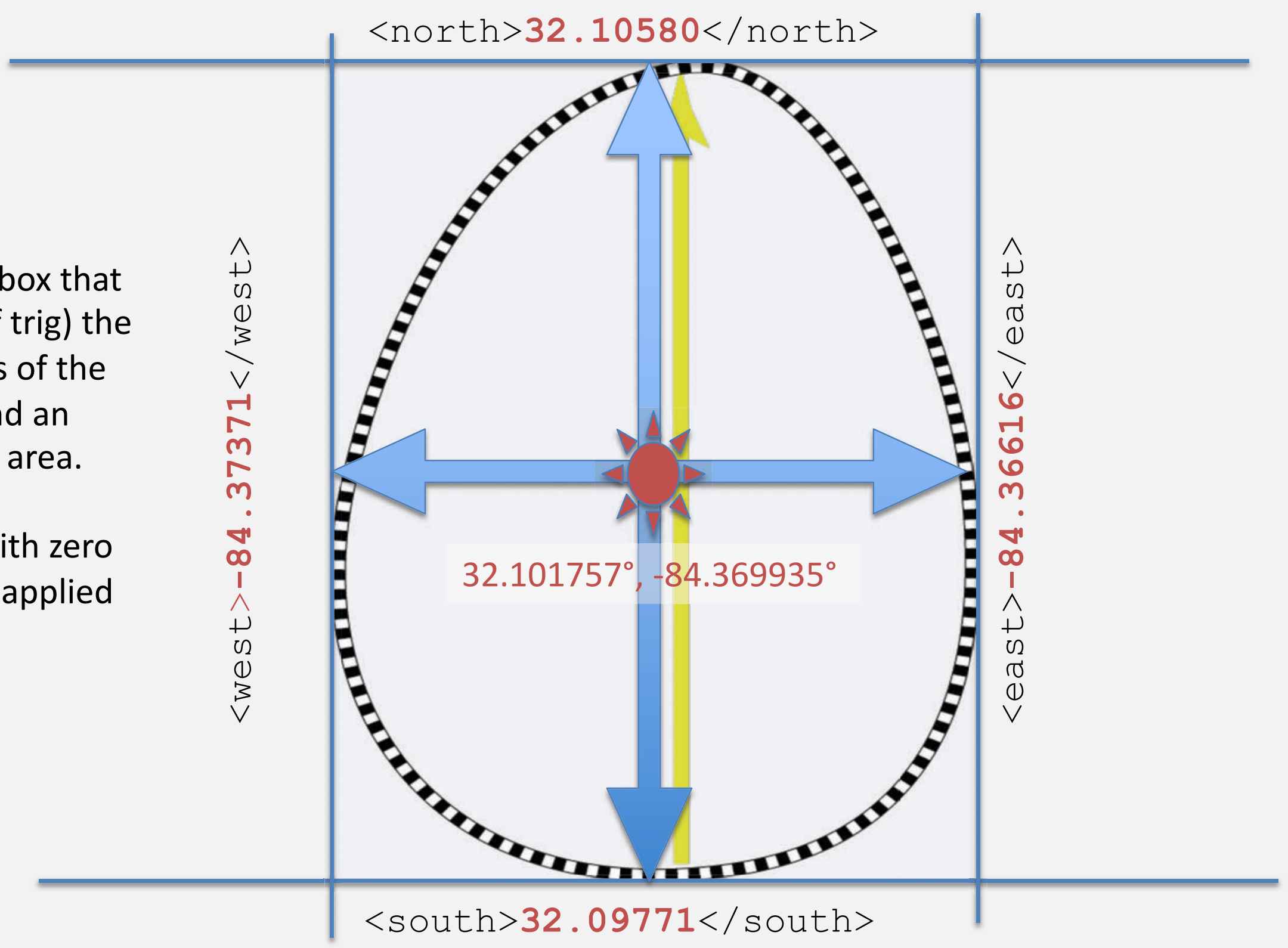




\section{Carolina bay Geospatial Survey}

\section{Comprehensive Survey of Carolina Bay Landforms}

\section{8}

Their very randomness of grouping and scatter demands an explanation. As a statistical phenomenon, they deserve to be studied statistically.

A detailed survey of all Carolina bays is underway here. Using facilities within Google Earth to position and fit an "image overlay" measurement template over the hsv-shaded DEM maps I produce, spatial metrics have been generated for a great quantity of Carolina bays. Measured and derived metrics of surveyed bays are publicly accessible using first link here. It offers access to the latest version of the resulting database, packaged as a tab separated values (TSV) file, one row per bay, and zipped for size reduction. This can be loaded into a database of your choice or imported into Excel. The last field in the database contains a plain-text kml-coded GE folder element containing a centroid placemark and the archetype image overlay element for that Cbay which enables the results of ad-hock and automated queries to be displayed in context on the virtual globe. As with all my Carolina bay work product, noncommercial use is encouraged, providing credit is included according to my Creative Commons

Attribution 4.0 International License.
- $\mathrm{Kml}$ starter file

- Lightweight, all data pulled from cloud

- 55,000 bays presented geospatially

- Placemark

- Measurement overlay

- Seamless high resolution topographic model

The Survey can be accessed at cintos.org/survey, where two download links are available. The fist will deliver a tab-separated text file with 55,000 plus rows, each contains metrics for a specific bay and a field which contains $\mathrm{kml}$ to view the bay on a virtual globe. 


\section{Carolina bay Geospatial Survey}

Visualization Tool Using Google Earth

Spatial maps are assomblod as Quadrants, Which are $1{ }^{\circ}$ of Longitude wide and $1^{\circ}$ of Latitude high, as currenty described by he USGS, and are our top-most organizational element. In order to provide reasonable sized elements for high resolution LIDAR-quality maps (1 to 3 meter grids), we have

subdivided each quadrant into sixteen (16) "Hextants" (our term).

Discussed here is the second visualization of the survey. The first version, started in 2011, leveraged the Google Fusion Table geospatial survey facility to feed individual bay features into Google Earth from a cloud-based repostory based on queries diven by Google Earth. As of $2 / 2019$, Google has shuttered hosion

The images below illustrate how the KMZ maintains efficiency by leveraging the regionalization

technology. As the user zooms in closer to the earth, increasingly higher resolution data is presented.

Bays are triaged into the top $10 \%$ by size, then the next $40 \%$, and finally presented at the closest 700 . are the last $50 \%$. If there are less than 100 bays in the $1 / 4^{\circ}$ region, all bays all are presented at the

second leve.

The entire survey has now been transcribed into the V2 format, and the link shown here will bring the Survey visualization into Google Earth. By refreshing this link, the latest version available can be

accessed. When renewing your copy, it may be best to flush the cache on your Google Earth instance to to prompt access to new version of these files. As of June, 2020, the survey has identified, measured and mapped $\sim 57,000$ bays.

Over the past few months, I have been experimenting with different false-color tables for the hs shading. The currently (July 10, 2020) set of maps uses a 10-meter cyclic color ramp, which provides a (a) 10 meters.

\pm Download 235
- 55,000 row tab- separated data file

- First 10 columns contain metrics for each bay

- Last column contains $\mathrm{kml}$ formatted text

- $\mathrm{kml}$ has placemark with popup

- measurement overlay

v v $125337-0476$

$\checkmark \underline{125337-0476}$

Major Axis 700 meters

Bearing

$\sqrt{\sim} \geqslant 125337-0476$

The second link on the page will deliver a lightweight starter $\mathrm{kml}$ file to load the geospatial survey into Google Earth.

All survey data loads from the cloud. 


\section{Hypothesis Inspiration}

North Carolina Geologists Gamble, Daniels and Wheeler spent a decade scouring the coastal plain trying to identify the providence of undatable deep surficial sediments. In this paper, they made the assertion that has framed my entire 15 years of research. As the opening sentence.

"The Carolina Bays of the Coastal Plain of North Carolina are surface features formed during deposition of the surficial sediments."

The bays examined in this study and those examined by Bryant (1964) Preston and Brown (1964), and Thom (1970) are clearly surficial features without subsurface expression.

This suggests that the primary depression, regardless of its original shape, was probably formed as a part of the final phase of the process of deposition of the surficial sediments.

Gamble, Daniels \& Wheeler, 1977, Primary And Secondary Rims Of Carolina Bays, Southeastern Geology, V18 No 4 https://libres.uncg.edu/ir/asu/f/SoutheasternGeology Vol18 No04 1977.pdf

In the intervening five decades, no one has undertaken a comprehensive

follow-up using today's geochron tools to date those sediments. 


\section{Novel Catastrophic Theory}

Carolina bays are not ephemeral, wispy landforms, but rather are the artifacts of a massive sedimentary depositional event 788,000 years ago.

We speculate on a high-energy, catastrophic deposition mechanism, where successive sheets of pulverized clastics were spread as mass geological flows from a near-tangential cosmic impact upon the Laurentide Ice Sheet at the MidPleistocene Transition, 788 ka $\pm 2 \mathrm{k}$.

The bay depressions are posited to be surficial dimples or voids in the blanket, perhaps artifacts of cavitationproduced bubbles frozen in time as the depositional energies relaxed and the sand transited from liquefaction to lockup. The "foundational rim" of each bay demonstrates an increased resistance to fluvial sheet erosion.

Successive sheets terminated closer to the distant impact site, evidenced as meter-scale "stair-steps" at the toe of each sheet.

The ejecta's arrival vector are evidenced in the orientation and distortion of the bubble. 


\section{Lots to complain about}

The hypothesis has numerous Challenges, which have been debated in many venues.

I maintain most of these are either incorrect or irrelevant in the context of the hypothesis, but let's look at the last two

1. "must be young because there is no erosion!"

2. "dating of bay sediments does not supported a singular event!"

3. "bays are too shallow and not round as required by an impact event"

4. "but I read that Kaczorowski was right!"

5. "their geomorphology is identical to landforms elsewhere"

6. "they don't look that old!"

7. "there are no depositional sheets across terrace boundaries" 


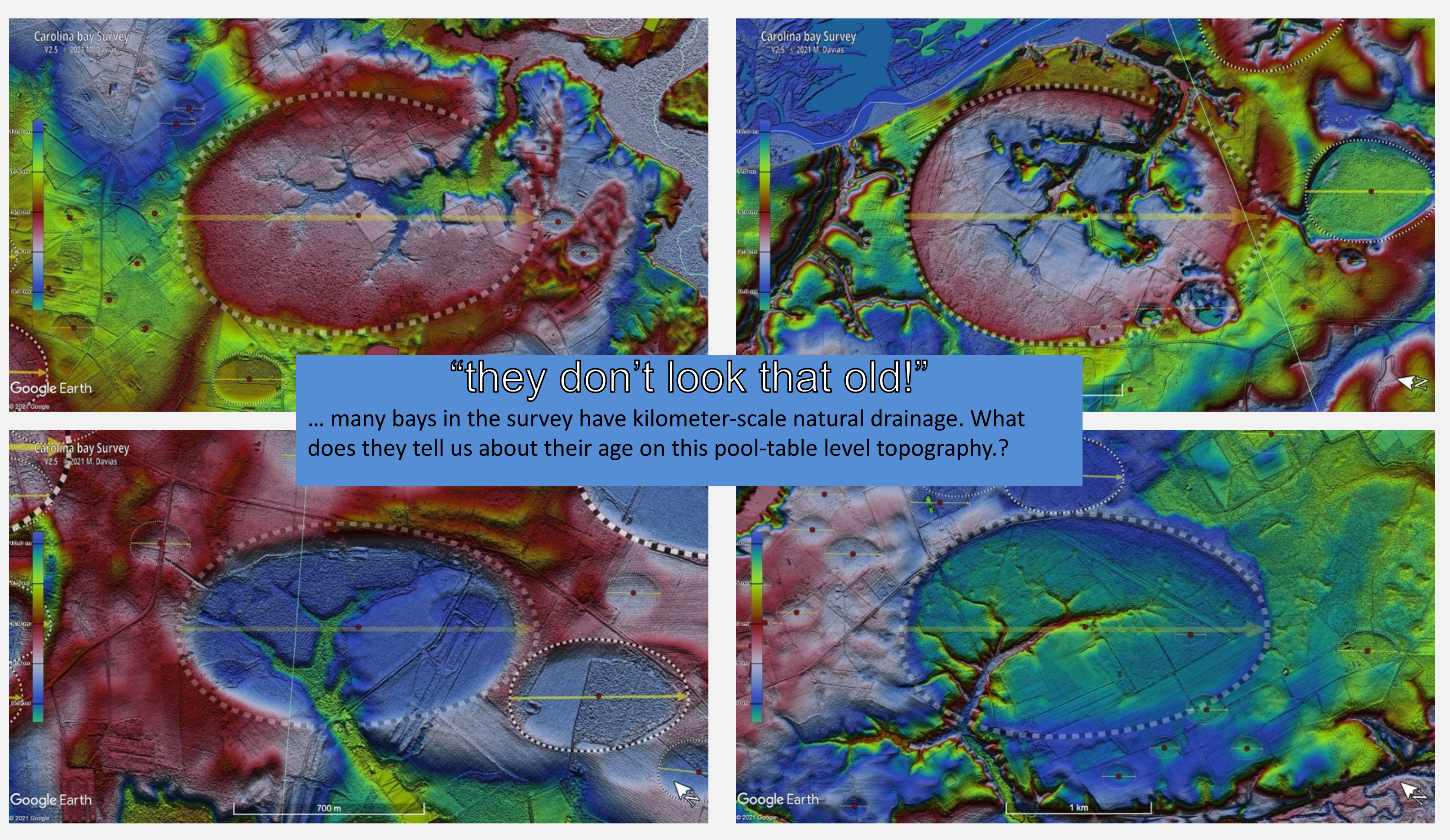




\section{"...there are no depositional sheets across terrace boundaries"}

"The Brandywine, Coharie, and Sunderland MSU are delineated largely on the basis of the Kenly and Wilson Mills scarps (Table 1), which break the Middle Coastal Plain into three major surfaces. Earlier workers mapped these MSU as separate formations, but little proof has been presented that indicates one way or another what happens to the units across these scarps."

"Based on the general characteristics of the sediments, and the absence of conclusive evidence of any significant lithologic changes of sediments across the scarps in all areas, we believe that the surface deposits in the Middle Coastal Plain in our area are one formation, not three as previously believed."

R.B. Daniels, E.E. Gamble, W.H. Wheeler, C.S. Holzhey, 1972, Carolina Geological Society Guidebook for 1972 Annual Meeting

The literature contains numerous examples of excellent research into the "Post Miocene" deposits from Maryland to Louisiana, each ending with a call to do further work to identify their temporal and depositional aspects.

I sense the same issue in the Dougherty Plains "residuum" 
Ancestral Dougherty Plain

Dendruictic Drainange

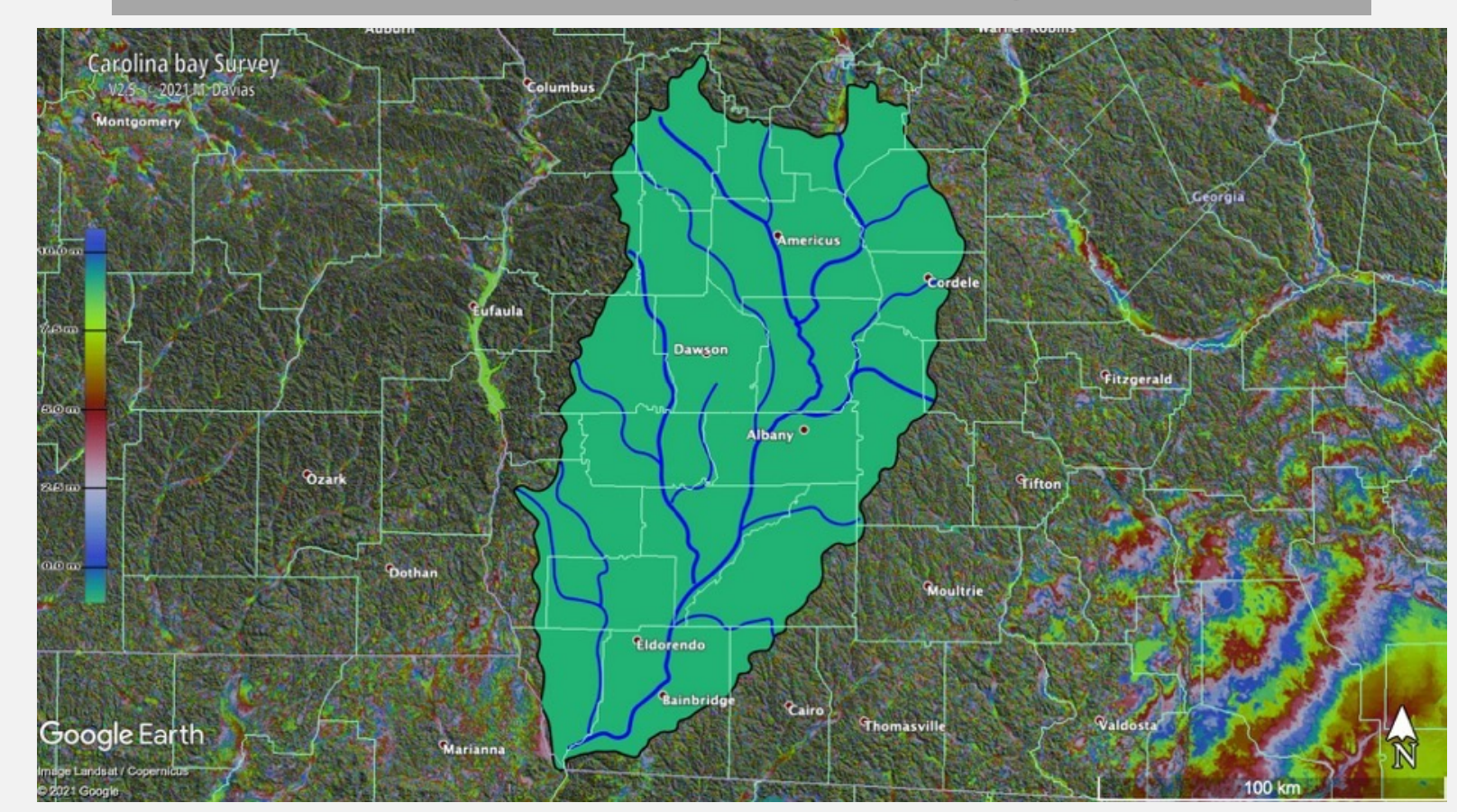

Allow me to whisk us back to the Mid Pleistocene, 800,000 years ago,

when an ancestral dendritic drainage pattern had expanded north from the Gulf across the Dougherty Plain topographic province.
Catลastrophic resurfacing @ 800 ka 1h-20 m of regolith

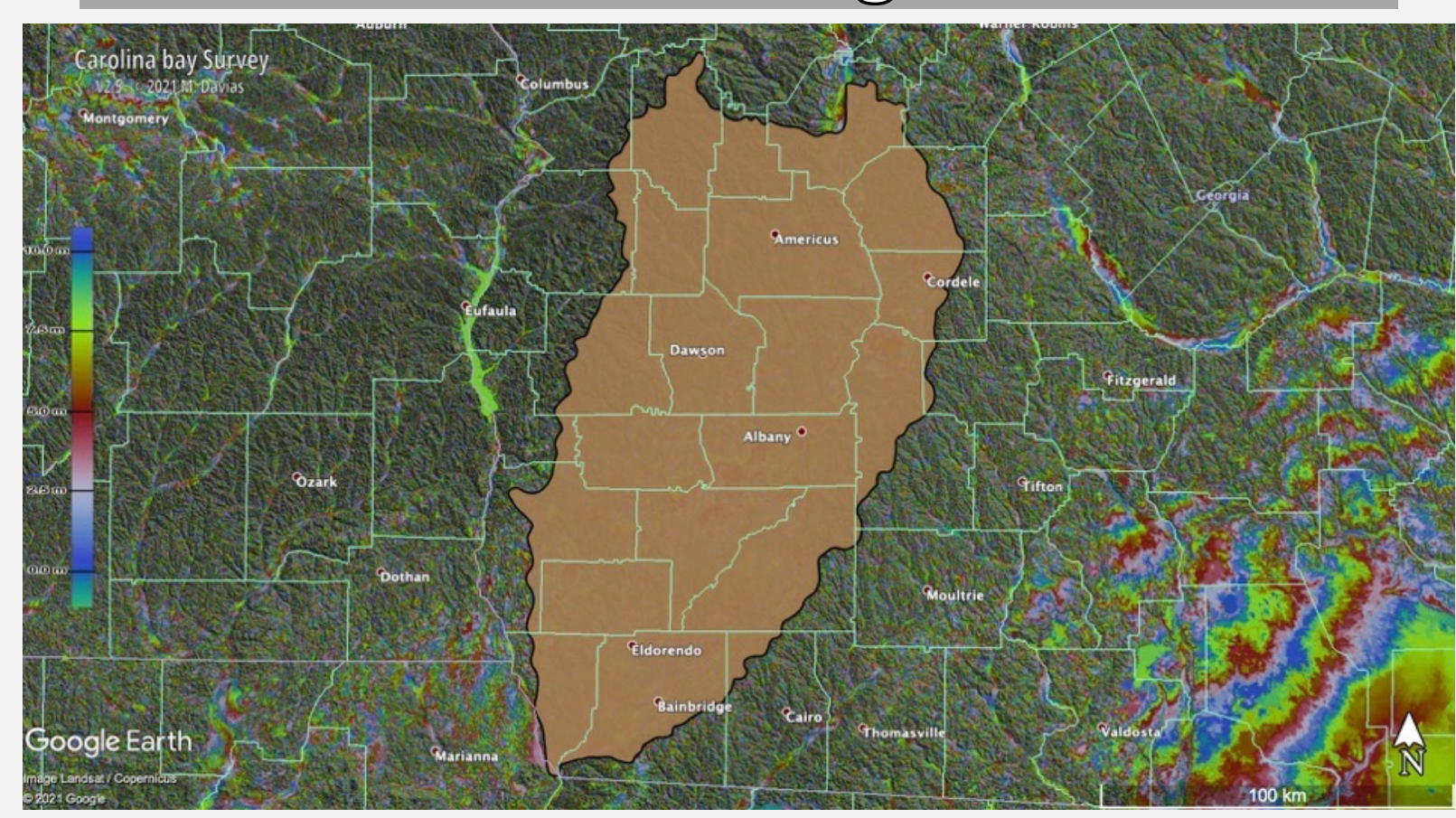

I now invoke a Catastrophic event which resurfaces the plain with 1-20 m of regolith currently characterized as residuum. Deposition is in blankets fining upwards and is conformable to paleo terrain features. 
Carolina bays manifested in new \{errace surface

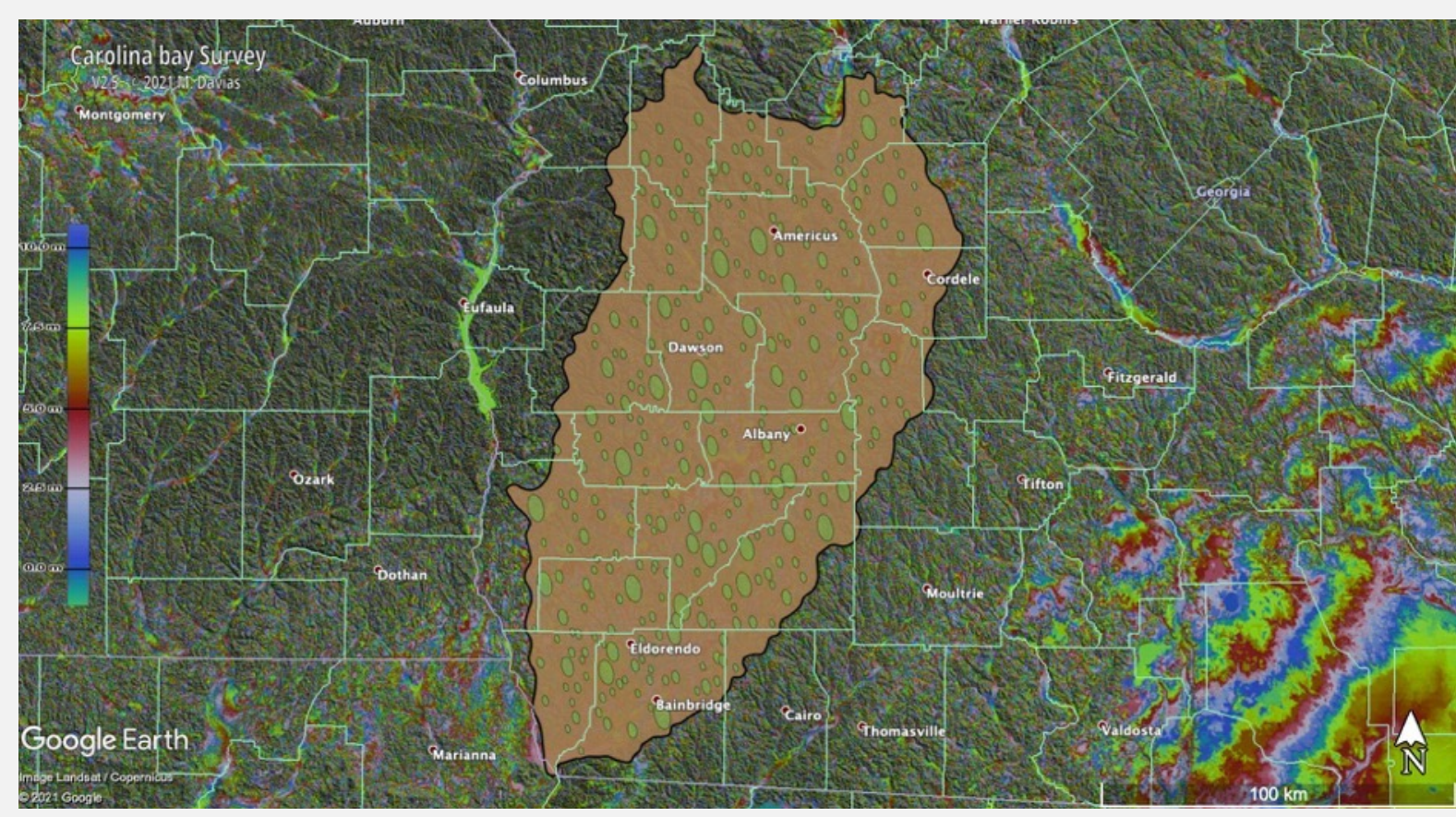

Carolina bays are manifested in new terrace surface, turning a significant \% of the landscape into hydraulically closed capture basins.
Deranged Drainage evolves, avoi̊ding Carolina bays

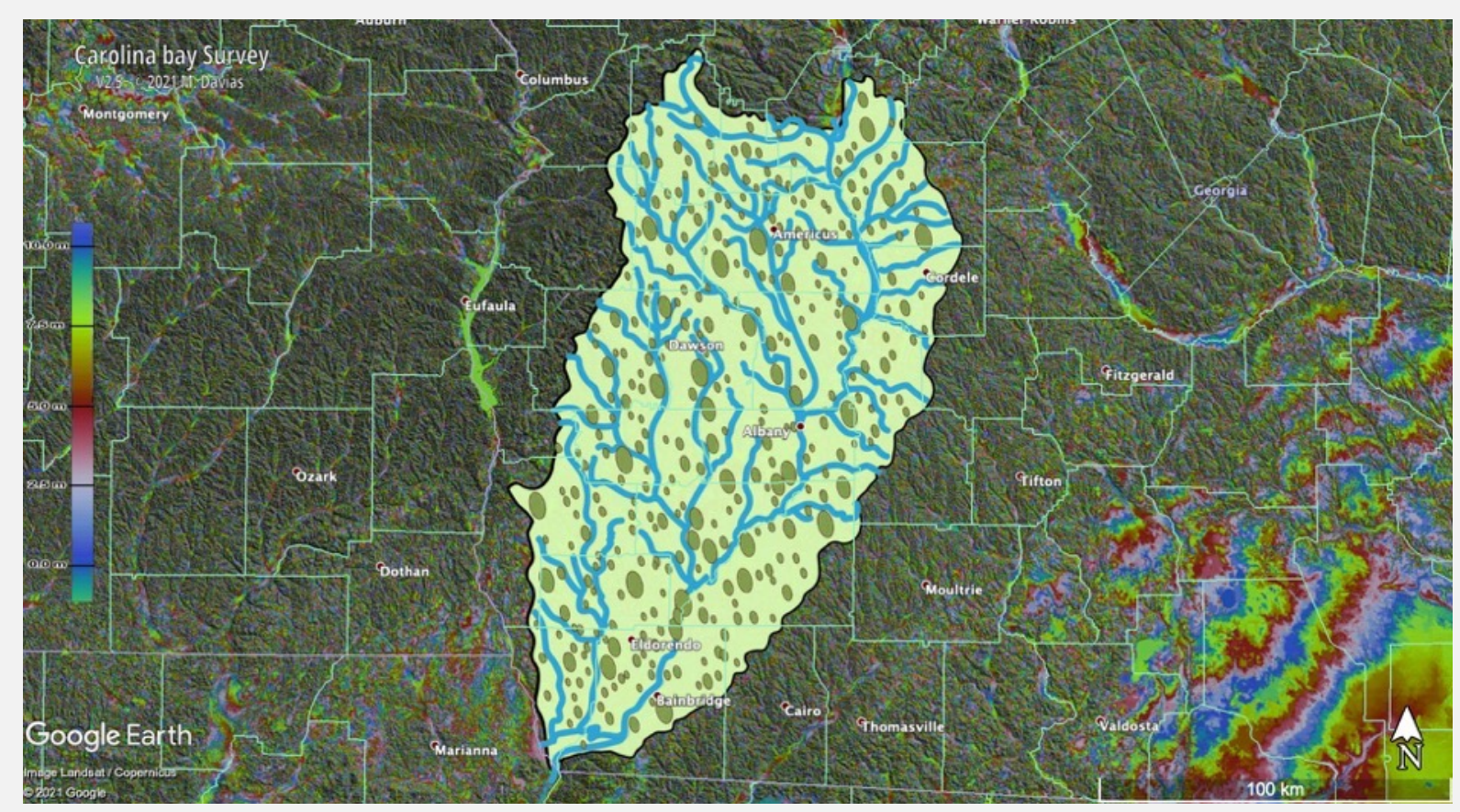

Deranged Drainage evolves. It is my interpretation that bays do not "develop on interfluvials", but rather Fluvial evolution is constrained by erosion-resistant bay rims which captures all incoming precipitation, thus drainage can only develop around the Carolina bays. 


\section{Implications for Dougherty Plain drainage pattern evolution}

- Paleo drainage channels buried

- The presence of numerous Carolina bay catchments reduces runoff \& erosion

- Deranged drainage network re-grows across resurfaced plain, deflected around erosion-resistive bay rims

- Occasionally recapturing antecedent drainage resulting in deeply incised channels

- Dolines form in new residuum through normal dissolution

- Carolina bays hold and concentrate standing water, encouraging karst penetration to Ocala bedrock

- Carolina bays which have been ditched may effectively puncture aquitard and accelerate karst dissolution beneath

- Buried paleochannels offer alternative mechanism for N-S doline alignment instead of fractures in the underlying Ocala bedrock 


\section{Falsification}

This hypothesis is falsified if geochronology of previously undatable Central and Eastern United States "Post Miocene" sediments do not document a deep isochronous pulse of regolith aggregation circa $800 \mathrm{ka}$.

This an assessment that can be accomplished with BerylliumAluminum burial dating which dates geological deposits by measuring pairs of rare nuclides produced from a quartz grain at a fixed ratio during cosmic-ray bombardment of a quartz-bearing mineral target. 


\section{Cosmic Ray Splitting Quartz Grain}

- Each grain of quartz split yields Beryllium and Aluminum isotopes in a know ratio

- $\mathrm{Be}^{10} \& \mathrm{Al}^{26}$ have differing half lives

- $\mathrm{Be}^{10}-\mathrm{Al}^{26}$ analysis can identify burial dates back 5 million years

- Range is required to accurately identify surficial sediment deposition across the MPT

- $\mathrm{C}^{14}$ good only to $\sim 50 \mathrm{ka}$

- OSL good only to 140 ka

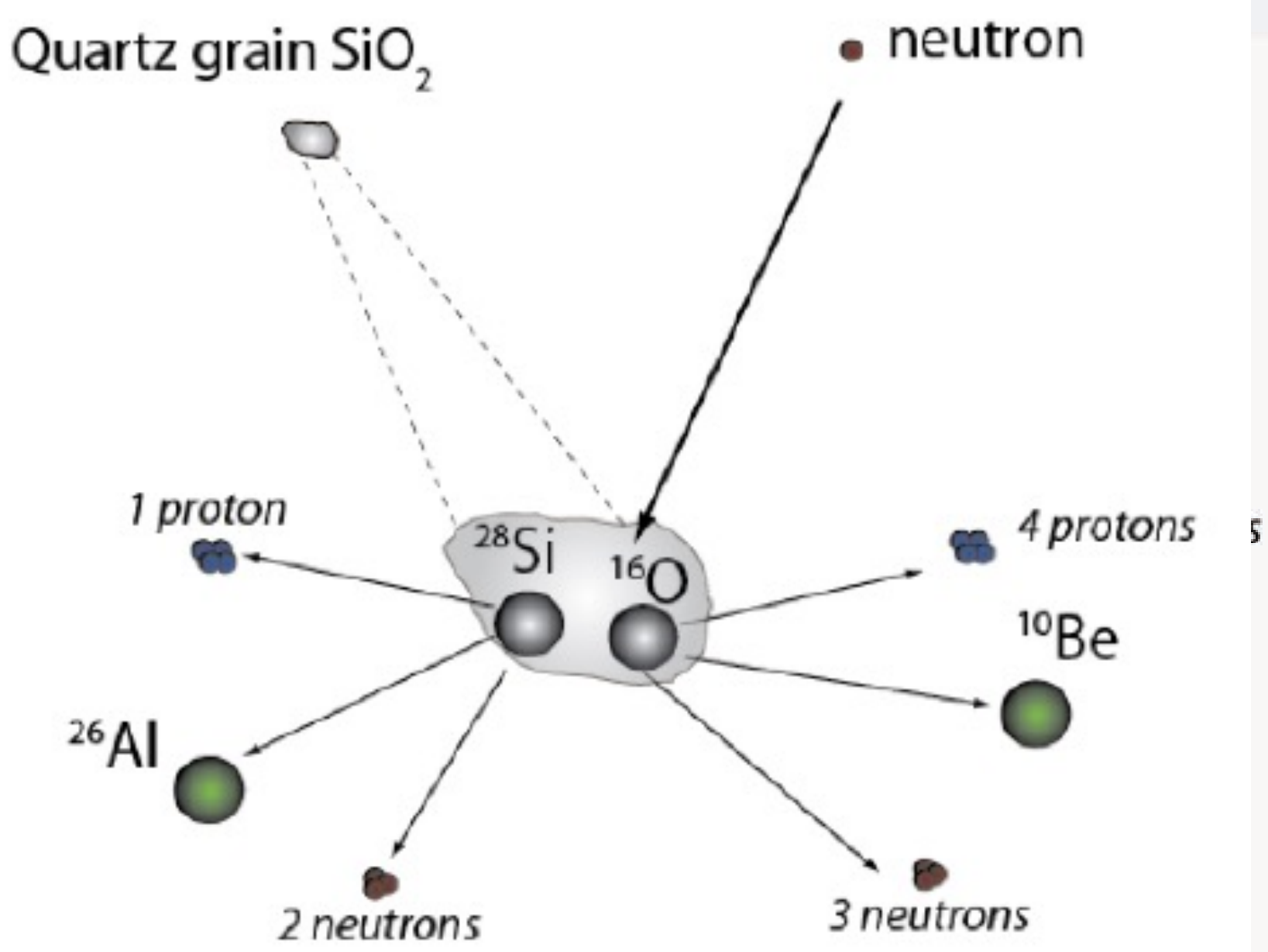

(Balco and Rovey, 2008) 


\section{Dating the Regolith Impulse using $\mathrm{Be}^{10} / \mathrm{Al}^{26}$}

I encourage more researchers to delve into this dating technique. If there is any merit to the proposal, there will be more examples such as these:

- Balco ${ }^{1}$ noted anomalous regolith loading in glacial tills deposited at $\mathbf{8 0 0} \mathrm{ka}$

- Anthony² Noted a widespread, anomalous, Appalachian drainage basin aggradation signal at $\sim \mathbf{8 0 0} \mathrm{ka}$

- Del Vecchio ${ }^{3}$ Identified a sudden onset of regolith circa 750 ka in a Central Appalachia bog trap basin previously only accumulating saprolite

Full disclosure, these results interpreted by the authors as by-products of the Mid Pleistocene Climate Transition.

1. Balco, Stone \& Jennings, Fate of the preglacial regolith beneath the Laurentide Ice Sheet, unpublished

2. Darlene M. Anthony And Darryl E. Granger, 2006, Five million years of Appalachian landscape evolution preserved in cave sediments, Geological Society of America, Special Paper 404

3. Joanmarie Del Vecchio, et al, Pleistocene Climate-Modulated Erosion: Interpretations From Cosmogenic Nuclide Concentrations Of An 18 M Sediment Core In Central Appalachia, this meeting Session No. 44 - Booth\# 301 
In another Daniels, Gamble and Wheeler paper, they investigated a 10 meter high, $20 \mathrm{~km}$ long ridge of "monotonous sand" containing Carolina bays. They struggled to identify its depositional regime. This is their closing sentence:

\section{"But, until much more is known about all the middle Coastal Plain, the Goldsboro} ridge will remain, in the last analysis, an enigma."

50 years ago, geology only offered gradualist mechanisms to be tested against. The Coastal Plains deserve extensive efforts to constrain its temporal aspects over the last 5 million years. This would be the ideal location replicate their extensive coring program across those two transects.
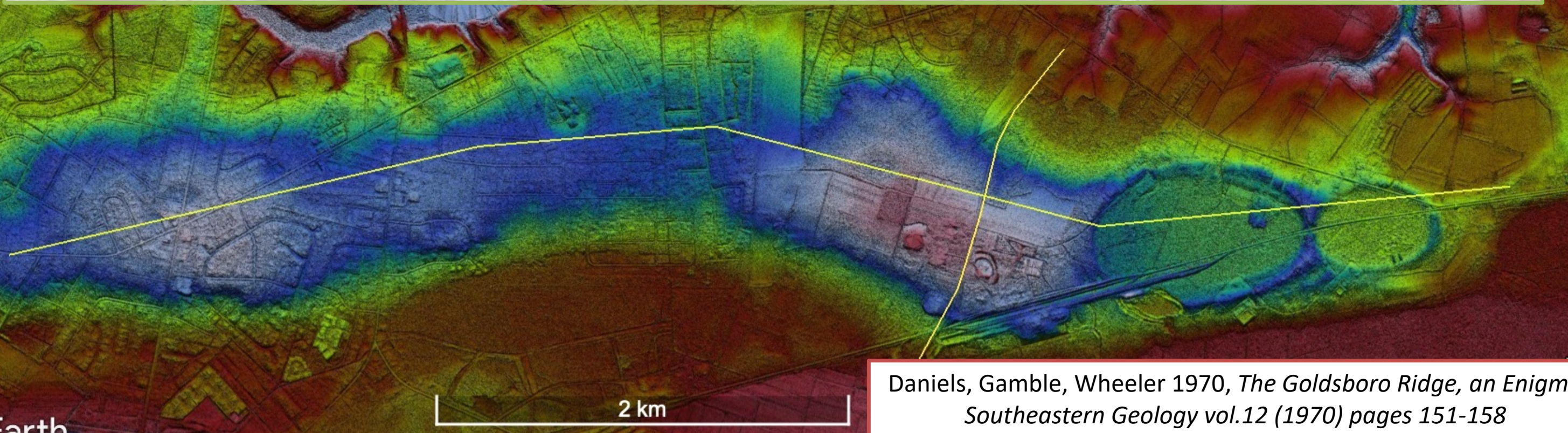


\section{Summary}

Dougherty Plain Catastrophically Resurfaced 800Ka

Dougherty Plain Contains Carolina bays

Deranged drainage network evolves constrained by Carolina bays

Carolina bays may deteriorate into dolines

Ancestral drainage may survive as buried channels

Deep Coring $(>10 \mathrm{~m}$ ) required to identify deposits controlling surface expression

${ }^{26} \mathrm{Al}-{ }^{10} \mathrm{Be}$ burial dating reaches back beyond limits of classic dating tools 


\section{Dolines and Carolina Bays on the Dougherty Plain}

A Carolina bay survey has measured $~ 25,000$ gentle depressions conforming to an egg-shaped 'baySouth' planform located along the coastal plains from mid-South Carolina clockwise through the Gulf Coast region. Their orientations rotate from NW-SE to N-S, respectively. They are prominent on low relief landscapes, a description that applies to the Dougherty Plain topographic province within the Apalachicola-Chattahoochee-Flint River Basin. Numerous doline/karst depressions are present within the undated (post Miocene) surficial sediments which mantle the plain. While some dolines host vernal ponds as hydraulically closed basins, many have penetrated down into the Upper Floridan Aquifer within the underlying Eocene Ocala limestone strata and function as sinks. New LiDAR-quality elevation data offers better discrimination between depressions conforming robustly to the baySouth planform shape/orientation and the more randomly shaped and randomly oriented dolines.

An unconventional hypothesis is offered for the depositional mechanism of the Quaternary member of the Dougherty Plain's residuum, informed by the work of Daniels, Wheeler and Gamble from the 1970's. In their extensive studies, Carolina bays are asserted to be topological artifacts created during the final stages of deposition of the Coastal Plains strata they are formed within. Their analysis regarding the nature of that deposition was tested against many gradualistic processes but left unsettled. Here, a catastrophic deposition of regolith is invoked to bury an antecedent Dougherty plain and its mature dendritic drainage, effectively repaving the low relief province and instantiating a deranged drainage pattern. Such a geomorphological history may explain the existence of buried hydrological flow paths that allow ground water to mobilize and trigger linear-sequences of dolines. Also explained would be the existence of highly incised streams, where antecedent channels are recaptured by the evolving deranged pattern. Carolina bays could metamorphose over time into karst landforms through the solutioning of limestone substrate by focused percolation of collected and perched waters. The hypothesis is falsified if cosmogenic nuclide 10Be/26Al dating of Post-Miocene sediment stratigraphic contacts disallows emplacement circa $800 \mathrm{ka}$.

Session 7 - D4. Watersheds Local to Global II: Understanding Natural and Anthropogenic Influences on Rivers, Wetlands, and Coastal Environments GSA Abstracts with Programs. Vol. 53, No. 2, 2021 doi: 10.1130/abs/2021SE-362256 